\title{
Effects of Gas Diffusion Layer Substrates on PEFC Water Management: Part I. Operando Liquid Water Saturation and Gas Diffusion Properties
}

\author{
Hong Xu, ${ }^{1}$ Minna Bührer, ${ }^{2}$ Federica Marone, ${ }^{2}$ Thomas J. Schm
and Jens Eller ${ }^{1, * *, \mathbf{z}}$ (D)
${ }^{1}$ Electrochemistry Laboratory, Paul Scherrer Institut, 5232 Villigen PSI, Switzerland
${ }^{2}$ Photon Science Department, Paul Scherrer Institut, 5232 Villigen PSI, Switzerland \\ ${ }^{2}$ Photon Science Department, Paul Scherrer Institut, 5232 Villigen PSI, Switze
${ }^{3}$ Laboratory of Physical Chemistry, ETH Zurich, 8049 Zurich, Switzerland
}

Gas diffusion layers (GDLs) are commonly known as one of the critical water management components in polymer electrolyte fuel cells with significant impact on the electrochemical cell performance. Increasing levels of liquid saturation in GDLs, especially during high-current-density operation, limit gas transport from the flow field channels to the catalyst layer surfaces and hence reduce cell performance. To provide GDL material selection and modification guidelines, a thorough understanding of the underlying structural factors of GDL materials and their influence on water management is required. In this work, operando X-ray tomographic microscopy (XTM) was employed to investigate the liquid saturation behavior for three commercial GDL materials during i-E curves and current jump characterization. Liquid volume fractions, saturation profiles and cluster distributions were analyzed to understand observed discrepancies in cell performance. Furthermore, saturation-dependent relative diffusivities were derived via direct numerical simulations, and the impact of GDL substrates on cell performance is thoroughly discussed with respect to structure and thermal properties.

(C) 2021 The Author(s). Published on behalf of The Electrochemical Society by IOP Publishing Limited. This is an open access article distributed under the terms of the Creative Commons Attribution 4.0 License (CC BY, http://creativecommons.org/licenses/ by/4.0/), which permits unrestricted reuse of the work in any medium, provided the original work is properly cited. [DOI: 10.1149/ 1945-7111/ac1035]

Manuscript submitted April 9, 2021; revised manuscript received June 14, 2021. Published July 26, 2021. This was Paper 1409 presented at the Atlanta, Georgia, Meeting of the Society, October 13-17, 2019.

In polymer electrolyte fuel cells (PEFCs), the gas diffusion layers (GDLs) are the critical component providing diffusion pathways for reactant gases from the flow field (FF) channels to the catalyst layer (CL) surface, and control the water removal. ${ }^{1}$ In common practice, GDLs are fabricated using a hydrophobically-treated carbon fiber substrate coated with a carbon black microporous layer (MPL). ${ }^{2}$ Both experimental and modelling work in the community confirmed that the GDLs are a critical component for the water management, especially at high-current-density operation, contributing significantly to the cell performance. ${ }^{3-12}$ Combining the GDL with a MPL is known to improve the cell performance ${ }^{13-15}$ and enhance the stability of the power output. ${ }^{14}$ Nevertheless, the individual effects of GDL substrate and MPL need to be understood and validated separately with controlled experiments.

X-ray tomographic microscopy (XTM) has been increasingly utilized in the past decade as a noninvasive technique for the characterization of the liquid water distribution in PEFCs, providing 3D volumetric information with GDL pore structures resolved in the micrometer range. The XTM technique has been reported extensively in the literature for ex situ structural characterization of GDL materials for determination of porosity, ${ }^{16-22}$ permeability, ${ }^{23,24}$ tortuosity ${ }^{16}$ and anisotropy. ${ }^{20,23}$ XTM setups for water injection in GDLs were developed ${ }^{25-29}$ to investigate ex situ water distributions in GDLs, to better understand the interactions between liquid water and the pore structures. For approaching realistic cell operating conditions, operando XTM setups have been further implemented ${ }^{3,4,30-32}$ to visualize liquid water distribution and probe saturation levels in GDLs. Though many attempts have been made towards understanding the GDL substrate properties and liquid saturation behavior, the reported operando XTM results in literature were limited to steady and quasi-static state and mainly focus on one or two selected types of GDL substrates. A systematic investigation of common GDL substrates and the impact of liquid saturation on cell performance is desired in the community for modelling validation and material optimization. ${ }^{33,34}$

\footnotetext{
*Electrochemical Society Fellow.

**Electrochemical Society Member.

${ }^{\mathrm{z}}$ E-mail: jens.eller@psi.ch
}

The aim of this work is to evaluate the underlying critical structure factors of three representative GDL substrates on PEFC performance at the typical start-up temperature of $25^{\circ} \mathrm{C}$. All GDLs are used without MPL coatings to isolate the effects solely due to the GDL substrate variation. Subsecond operando 4D X-ray tomographic microscopy (XTM) is employed in a series of two manuscripts to fully capture the dynamic evolution of liquid distribution during i-E curve and current jump characterization. Through an advanced image processing pipeline, XTM volumes are segmented and quantified. The liquid saturation behavior and gas diffusion properties are derived to comparatively study the effects of the individual GDL structures and their impact on cell performance differences is elaborated. Later, in part II of this paper series, the XTM methodology presented here will be applied to investigate the influence of the three GDL materials on the characteristic drying phases after cell shutdown.

\section{Experimental}

Cell assembly.-A PEFC with an active area of $0.08 \mathrm{~cm}^{2}$ $(2.2 \mathrm{~mm} \times 3.6 \mathrm{~mm})$, designed by Eller et al. ${ }^{3}$ specially for imaging compatibility, was used for the XTM imaging experiments (see Fig. 1a). The flow field plates were made of graphitic material (BMA5, SGL Technologies) and have two gas channels for both anode and cathode with a width of $0.8 \mathrm{~mm}$ and a depth of $0.3 \mathrm{~mm}$. A catalyst coated membrane (CCM) with anode/cathode Pt loadings of $0.1 / 0.4 \mathrm{mg} \mathrm{cm}^{-2}$ from W. L. Gore Associates $\left(\right.$ Gore $^{\circledR}$ Primea $^{\circledR}$ A510.1/M815.15/C510.4 with a $15 \mu \mathrm{m}$ thick reinforced Gore-Select $^{\circledR}$ membrane) was used. The three types of GDL substrates were selected: Freudenberg H2315 I6 (10 wt.\% PTFE coating, Freudenberg Group), TGP-H-060 (10 wt.\% PTFE coating, Toray Industries Inc), and SGL 24BA (5 wt.\% PTFE coating, SGL Carbon), representing different substrate fabrications and increasing pore sizes. All selected GDL substrates were used without micro porous layer (MPL) for the purpose of isolating substrate effects. The cell temperature was monitored and regulated during the XTM imaging experiments by PT100 temperature sensors and heating foils inserted in the cell assembly. A compression level of nearly $16 \%$ was achieved for both anode and cathode GDLs with a compression unit made of PEEK material. 


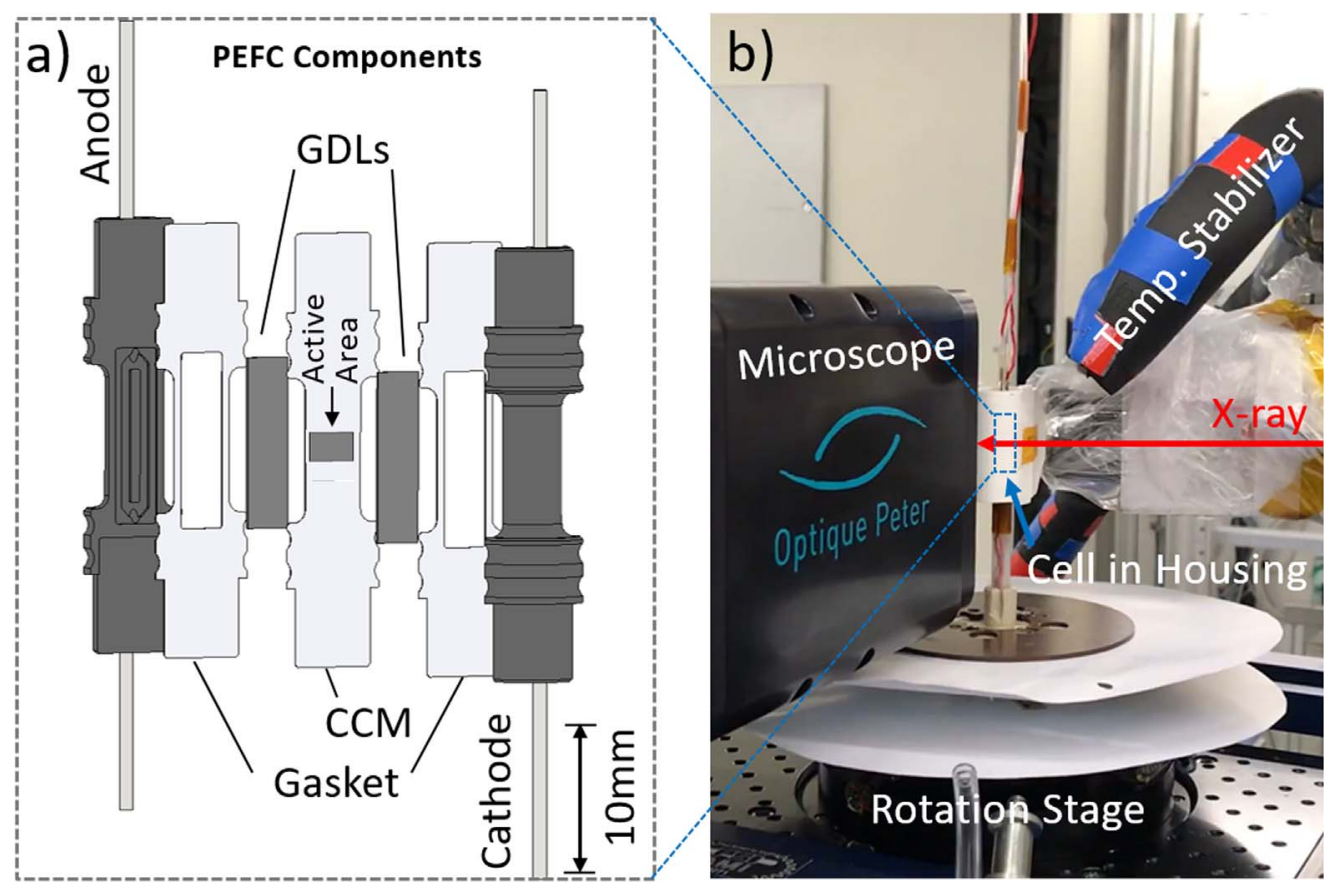

Figure 1. (a) Schematic of PEFC components; (b) operando XTM imaging setup with PEFC placed inside a housing.

Electrochemical characterization.-Three pristine PEFCs with the afore mentioned GDL substrates were pre-conditioned in the lab at $40{ }^{\circ} \mathrm{C}$ following a $24 \mathrm{~h}$ break-in protocol. ${ }^{4}$ Polarization curves were acquired during the break-in procedure to evaluate the performance improvements. During the beamtime experiments with $\mathrm{X}$-ray radiation, all cells were operated at $25{ }^{\circ} \mathrm{C}$ with $\mathrm{H}_{2}$ /air (relative humidity of $100 \% / 0 \%$, gas speed in channels of $3.5 / 3.5 \mathrm{~m} \mathrm{~s}^{-1}$ ). The anode gas was humidified through water immersed Nafion tubes with bath temperature regulated by a high thermal-precision thermostat (Haake Phoenix P1, Thermo Fisher Scientific, Germany), whereas the cathode gas was kept dry. All the gases were supplied from the top of the vertically mounted cell on the rotation stage with 2 meters long silicone tubes (see Fig. 1b) allowing for nearly 30 turns of continuous rotation in one direction. During the imaging experiments, polarization curves were collected with a current density step of $0.25 \mathrm{~A} / \mathrm{cm}^{2}$ and hold time of $15 \mathrm{~min}$ from open circuit voltage $(\mathrm{OCV})$ to maximum current conditions (constant voltage $100 \mathrm{mV}$ ). The current jump (CJ) experiments were performed with a current switch from 0 to $0.5 \mathrm{~A} \mathrm{~cm}^{-2}$ and keeping the same current density for $1 \mathrm{~h}$. All experiments were started by drying the GDL for $5 \mathrm{~min}$, then monitoring the invasion of liquid water into a dry GDL. The cell temperature was stabilized using a cell housing developed for freeze experiments ${ }^{35}$ with $25{ }^{\circ} \mathrm{C} \mathrm{N}_{2}$ gas flow circulating around the cell. The high frequency resistance (HFR) was recorded by a Tsuruga E3566 AC milliohm meter (Tsuruga Electric Co., Japan) at a frequency of $1 \mathrm{kHz}$.

Subsecond Operando XTM imaging.-Subsecond operando Xray tomographic microscopy (XTM) was employed to investigate liquid water saturation processes in the gas diffusion layers of PEFCs at the TOMCAT beamline of the Swiss Light Source (SLS) at Paul Scherrer Institut (PSI). Polychromatic radiation with $5 \%$ power of the incident beam from the $2.9 \mathrm{~T}$ super-bending magnet ${ }^{36}$ was used, allowing $30 \mathrm{~s}-60 \mathrm{~s}$ exposure of a single cell without significant electrochemical performance degradation. A polychromatic beam compatible $4 \mathrm{x}$ microscope (Optique Peter, France) ${ }^{37}$ coupled with the GigaFRoST fast camera readout system, ${ }^{38}$ provided a voxel length size of $2.75 \mu \mathrm{m}$. The field of view (FoV) was set to $1440 \mathrm{px} \times 1100 \mathrm{px}$ to cover the full activate area of the cell. A $150 \mu \mathrm{m}$ thick LuAG:Ce scintillator was chosen for converting polychromatic radiation to visible light. The XTM scan time was set to $0.1 \mathrm{~s}(0.33 \mathrm{~ms}$ exposure time, 300 projections $)$, in order to capture the fast liquid dynamics within the GDL and reduce X-ray dose so to enable multiple experiments with up to 300 scans

\begin{tabular}{|c|c|c|c|c|c|c|}
\hline \multirow{4}{*}{ i-E } & $15-30$ & 0.25 & & & & \\
\hline & $30-45$ & 0.5 & & & & \\
\hline & $45-60$ & 0.75 & & & 300 & 3 \\
\hline & $90-105$ & $\max$ & & & & \\
\hline \multirow[t]{3}{*}{ CJ } & $0-2$ & $0-0.5$ & & & 3 & 41 \\
\hline & $2-5$ & & & & 30 & 6 \\
\hline & $5-60$ & & & & 300 & 11 \\
\hline \multirow[t]{2}{*}{ Dry Ref } & End & 0 & $\mathrm{~N}_{2} / \mathrm{N}_{2}$ & 1 & 0 & 1 \\
\hline & & & $100 / 0$ & $(1000$ prjs $\times 1 \mathrm{~ms})$ & & 62 (max in total) \\
\hline
\end{tabular}




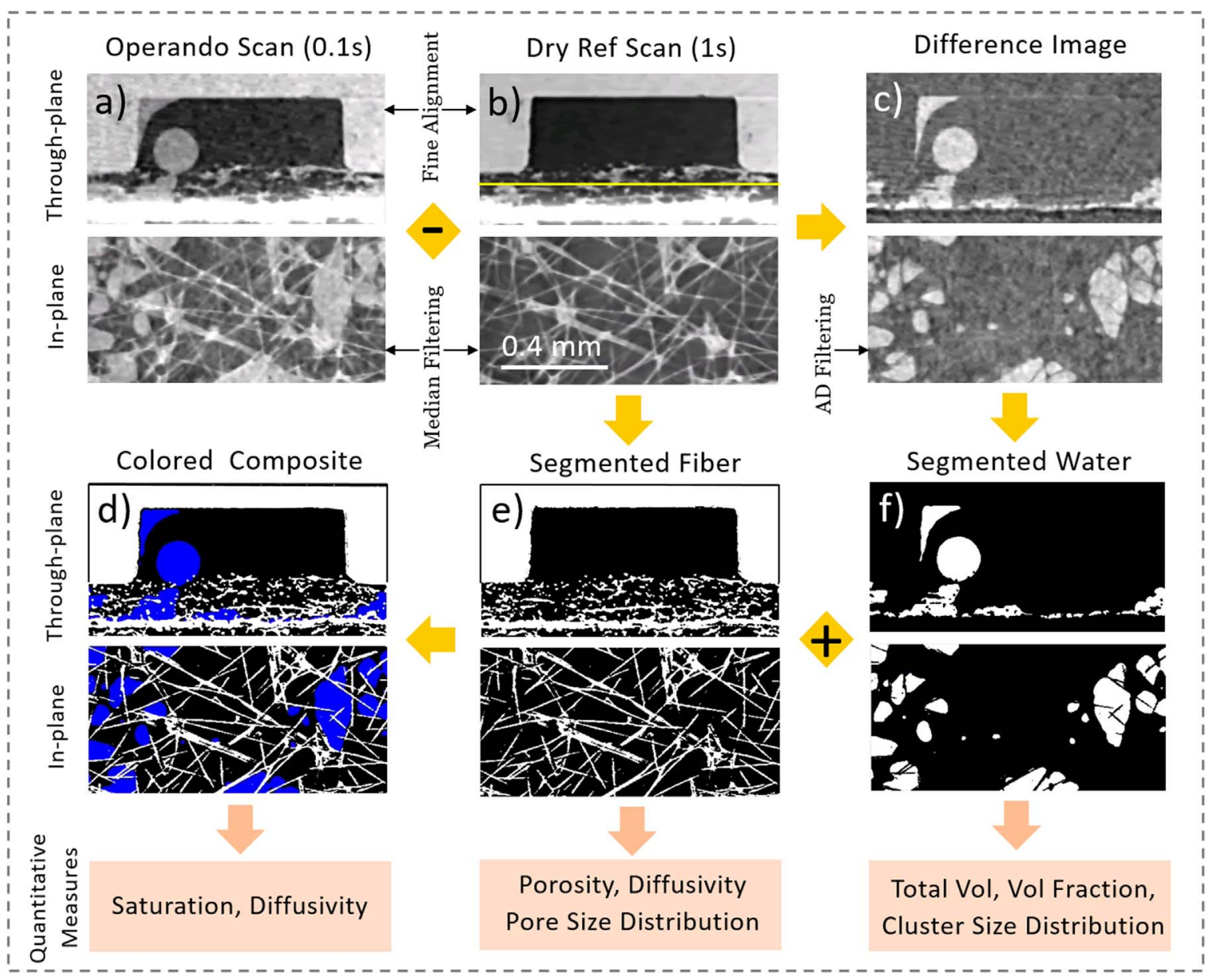

Figure 2. Image processing pipeline for operando fuel cell XTM imaging. A Toray substrate is used here as an example.

\section{Freudenberg 16}

a)

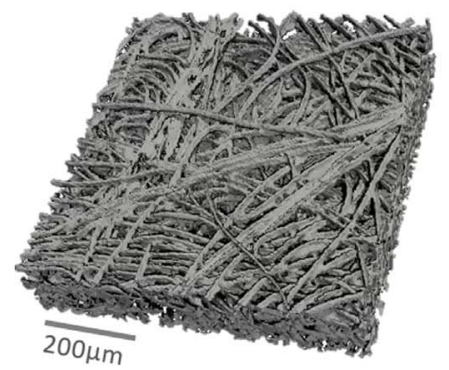

d)

$\mathrm{d} 1: 17( \pm 1.2) \mu \mathrm{m}$

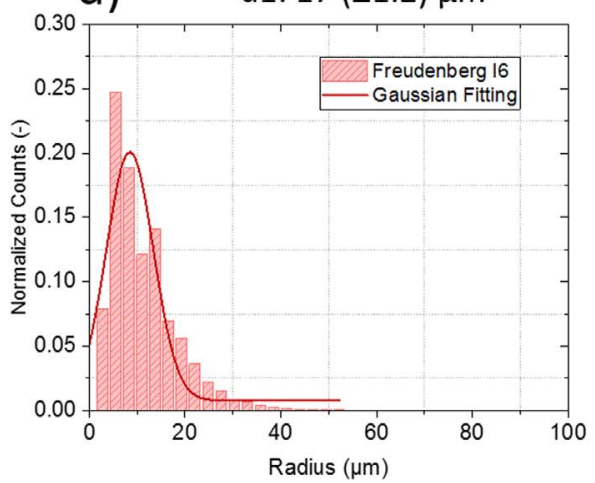

Toray 60

b)

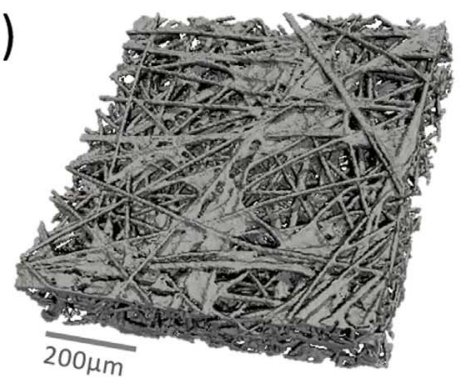

e)

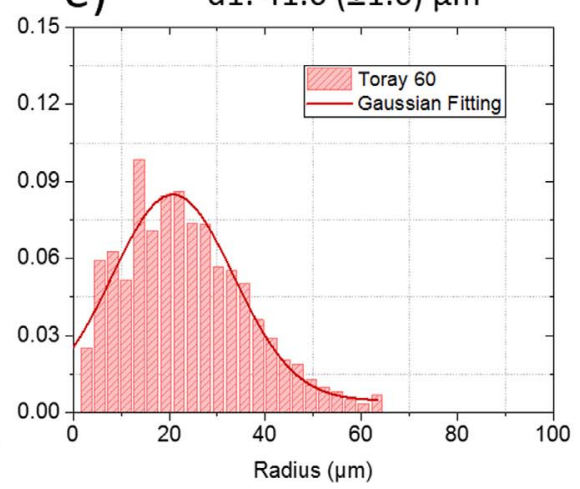

SGL 24BA

C)
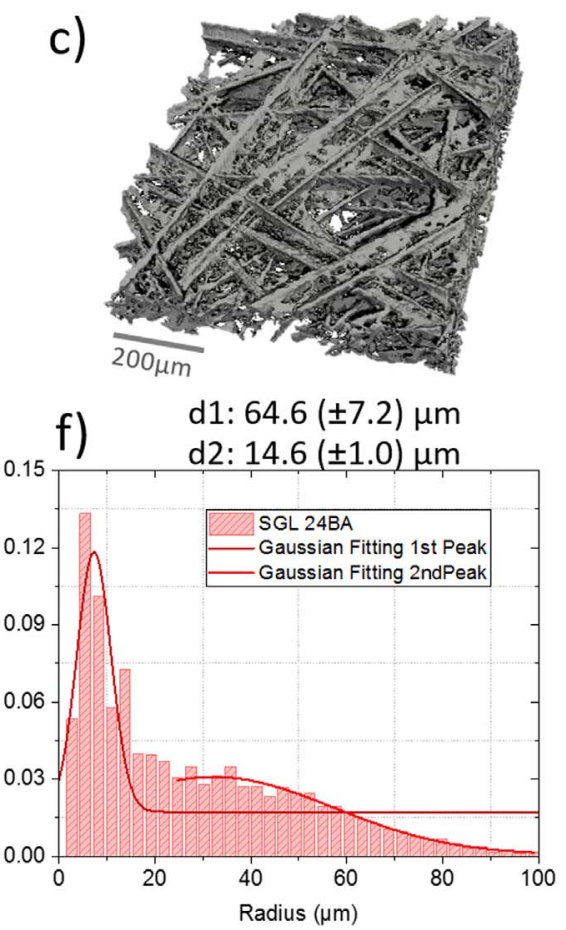

Figure 3. 3D renderings of three different GDL substrates (a) Freudenberg I6; (b) Toray TGP-H-060; (c) SGL 24BA) and their corresponding continuous pore size distribution (cPSD) with Gaussian fitting for peak position determination (d), (e) and (f), respectively. 


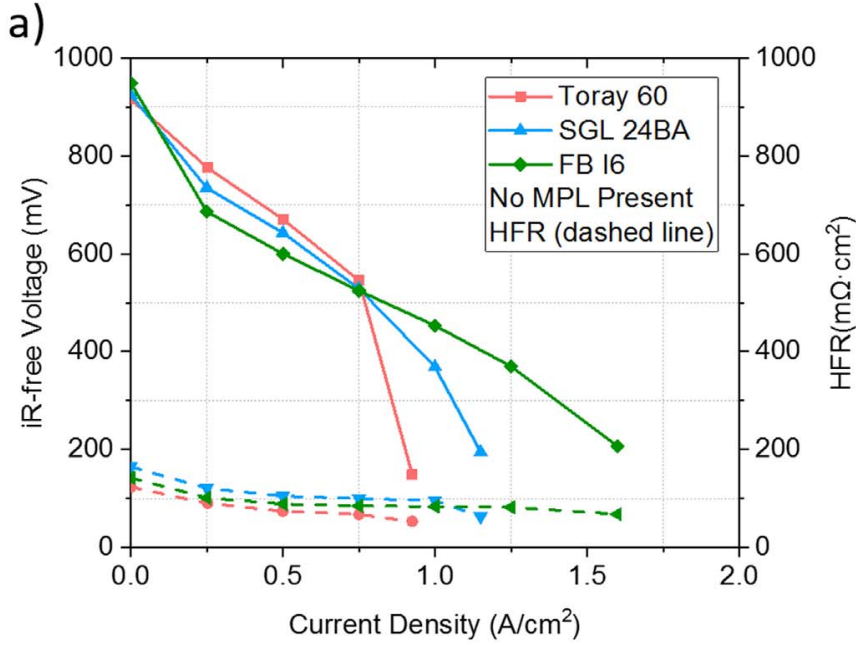

b)

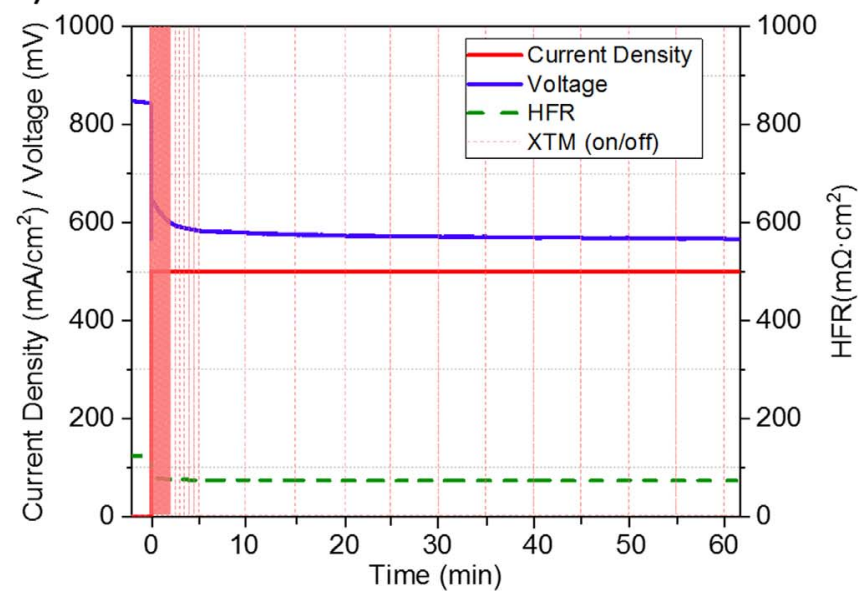

Figure 4. (a) IR-free i-E curves for PEFCs assembled with three different substrates (Toray TGP-H-060, SGL 24BA and Freudenberg I6); (b) Toray cell voltage and HFR profiles following a current jump from 0 to $0.5 \mathrm{~A} \mathrm{~cm}^{-2}$ for $1 \mathrm{~h}$. Dashed red lines indicate the distributed XTM scan pattern.

performed with a single cell. A high quality dry scan with a scan time of $1 \mathrm{~s}$ ( $1 \mathrm{~ms}$ exposure time, 1000 projections) was collected for every cell at the end of all experiments.

With an XTM scan duration of $0.1 \mathrm{~s}$, in total 62 scans were distributed during the operation of each cell as shown in Table I to explore water distribution during $\mathrm{i}-\mathrm{E}$ curve and current jump experiments. For each current step in the i-E curves, 3 scans were acquired during the $15 \mathrm{~min}$ holding time with an interval of $5 \mathrm{~min}$ During the $1 \mathrm{~h}$ current jump experiments, 47 scans were collected in the first 5 min to monitor fast water evolution inside GDLs, and 11 scans with time interval of $5 \mathrm{~min}$ were acquired in the later stage to follow the saturation behavior towards stagnation.

\section{Image Processing \& Quantification}

Image processing pipeline.-All radiographies acquired at the TOMCAT beamline were first preprocessed with the Paganin phase retrieval method ${ }^{39}$ and reconstructed into $3 \mathrm{D}$ volume data by Gridrec. $^{40}$ The parameters for the Paganin preprocessing $(\delta=$ 4E-07, $\beta=1 \mathrm{E}-10, \mathrm{~d}=0.02 \mathrm{~m}$ ) were selected to achieve high contrast between the liquid and void phase. As shown in Fig. 2, the cathode domain of the operando XTM scans $(0.1 \mathrm{~s})$ were registered to a reference high quality dry scan (1 s). Then the high quality dry scan was subtracted from the operando scans to isolate the water signal in the difference image shown in Fig. 2c. 3D median filtering with a kernel size of 2 px was applied on both the dry reference scan and operando scans before subtraction. Further, the difference images were filtered with an anisotropic diffusion filter ( 3 iterations) $)^{41}$ to suppress noise while preserving the edges of the liquid domains. After global thresholding at $50 \%$ position between the background and the liquid signal, water-only binary images were used to evaluate the total water volume, water volume fraction and droplet size distribution. In parallel, high quality dry scans were reconstructed using different Paganin parameters $(\delta=5 \mathrm{E}-09, \beta=1 \mathrm{E}-10$, $\mathrm{d}=0.02 \mathrm{~m})$ and filtered with an edge-preserving inverse scale space (ISS) filter ${ }^{42}$ (100 iterations, provided in KipTool ${ }^{43}$ ). GDL fiber structures were segmented from the filtered dry scans to calculate the porosity, dry structure diffusivity and pore size distribution. The above mentioned water-only binary images were masked with the inverted binary fiber structures to remove the misclassified water in the solid domains. With the combination of segmented GDL fiber structures and liquid water structures, saturation distributions and relative diffusivities in the presence of water can be determined. All image filtering and processing steps were programmed in Python unless otherwise specified.

Pore size distribution.-The pore size distribution (PSD) was obtained from the segmented fiber structures using the Xlib plugins developed by B. Münch ${ }^{44}$ in Fiji/ImageJ. ${ }^{45}$ It assigns to each voxel the radius value of the largest circle that fits into the pore domain. The histogram of radii is defined as the $2 \mathrm{D}$ continuous pore size distribution and fitted via a Gaussian peak fitting algorithm to derive the most common pore size for primary and secondary pores (in case of SGL materials) in different GDL substrates.

$2 D$ water volume mapping. $-2 \mathrm{D}$ projections of the water volume fraction distribution for the in-plane and through-plane directions were obtained by averaging and normalizing the segmented water voxels along the corresponding axis (in-plane/through-plane) to visualize the water saturation within the GDL via MATLAB scripts. The size of the selected cuboid domain in the GDL region was $1107 \mathrm{px} \times 710 \mathrm{px} \times 50 \mathrm{px}(3044 \mu \mathrm{m} \times 1953 \mu \mathrm{m} \times 138 \mu \mathrm{m})$, covering the center rib (CR), left channel (LC) and right channel (RC) areas. For the through-plane water distribution, the liquid water volumes in the channel domains were also included.

Through-plane water saturation profile.-The water saturation was calculated in terms of the amount of voxels labelled as liquid water in the segmented water mask divided by the amount of voxels labelled as void in the segmented fiber mask. It can be applied to each $2 \mathrm{D}$ in-plane slice to obtain a water saturation profile, or to the total GDL volume to obtain the total saturation. The region of interest for water saturation statistics was categorized as under the center rib (CR) and under the channels $(\mathrm{LC}+\mathrm{RC})$ with each cuboid domain of size $750 \mathrm{px} \times 250 \mathrm{px} \times 47 \mathrm{px}(2062 \mu \mathrm{m} \times 688 \mu \mathrm{m} \times$ $129 \mu \mathrm{m})$. The GDL domains under the borders of the center rib and channels were excluded from the evaluations. It is necessary to point out that in the case of complex SGL fiber and binder structures, most binder pores remain unresolved and are categorized as solid structure, resulting in lower than actual porosity values.

Cluster size distribution.-The water clusters of a sample volume were identified using the RegionProps function in the skimage Python package. ${ }^{46} 26$ possible neighbors by face, edge and corner of a center voxel center were considered as connected voxels within the same cluster. The volume of each identified single cluster was calculated for the region under the center rib (CR) within a cuboid domain size of $750 \mathrm{px} \times 250 \mathrm{px} \times 47 \mathrm{px}(2062 \mu \mathrm{m} \times$ $688 \mu \mathrm{m} \times 129 \mu \mathrm{m})$.

Relative diffusivity.-Relative diffusivity describes the resistance of diffusive transport through a porous media. Fick's first law expresses the diffusive flux of the gas $\mathrm{J}$ as: ${ }^{47}$ 
FB I6

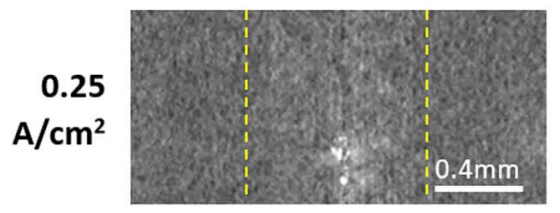

0.5

$\mathrm{A} / \mathrm{cm}^{2}$

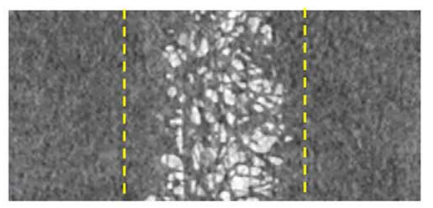

0.75

$\mathrm{A} / \mathrm{cm}^{2}$

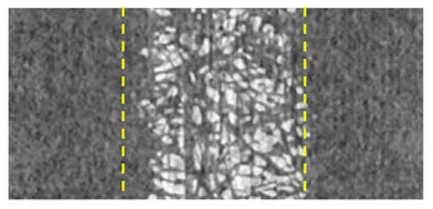

100

$\mathrm{mV}$

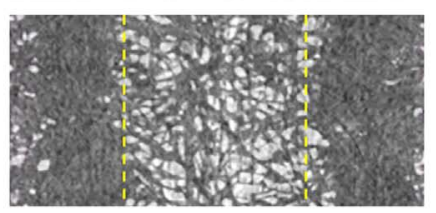

Toray 60
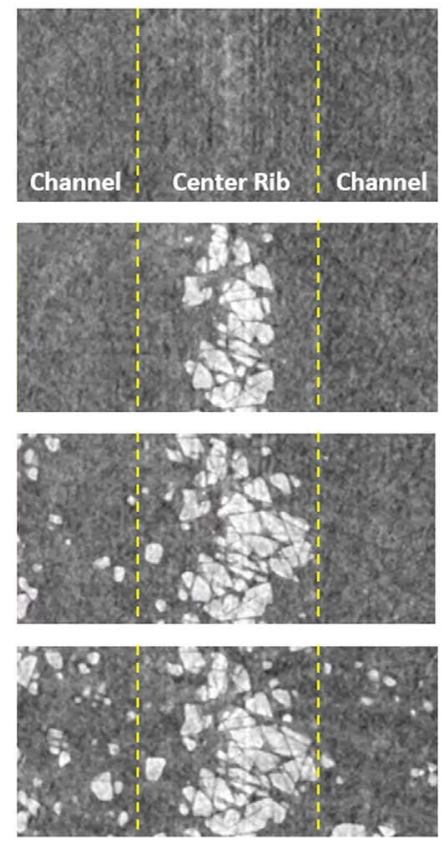

SGL 24BA
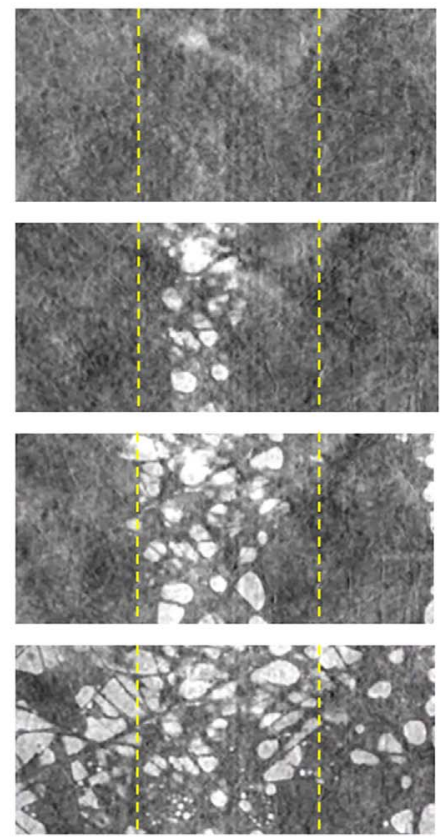

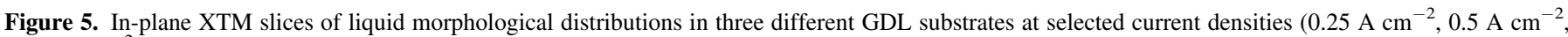
$0.75 \mathrm{~A} \mathrm{~cm}^{-2}, 100 \mathrm{mV}$ ) according to the i-E curves in Fig. 4a. The in-plane position is selected near to the catalyst layer.

$$
J=-\frac{\varepsilon}{\tau} D \nabla_{C}
$$

where $\varepsilon$ is the porosity and $\tau$ is the tortuosity factor of the material, $D$ is the bulk diffusivity and $\nabla c$ is the concentration gradient. The relative diffusivity $D_{r e l}=(\varepsilon / \tau)$ was obtained from the GeoDict ${ }^{\circledR}$ software (Math2Market GmbH, Kaiserslautern, Germany) utilizing the DiffuDict simulation Module, ${ }^{48}$ and calculated for both dry and partially saturated GDL structures. The saturation-dependent normalized relative diffusivity $D_{\text {norm }}^{r e l}$ was then calculated by:

$$
D_{\text {norm }}^{r e l}=(\varepsilon / \tau)_{s a t} /(\varepsilon / \tau)_{d r y}
$$

The analyzed domains were selected under the center rib (CR) and channels $(\mathrm{LC} / \mathrm{RC})$ with a cuboid dimension of $750 \mathrm{px} \times 250 \mathrm{px} \times$ $47 \mathrm{px}(2062 \mu \mathrm{m} \times 688 \mu \mathrm{m} \times 129 \mu \mathrm{m})$. The relative diffusivity was determined in both through-plane direction from the top of the GDL towards the catalyst layer and in-plane direction perpendicular to the flow field channels.

\section{Results}

GDL substrate properties.-The GDL substrate, as one of the essential component in PEFC assemblies, is known to have great impact on water management. Three commercially available GDL substrates (Freudenberg I6, Toray TGP-H-060, SGL 24BA) with representative fiber structures are shown in Fig. 3 as 3D renderings. Different pore morphologies with increasing average pore sizes can be visually detected. Continuous pore size distributions of each substrate are presented as quantitative measures (see Figs. 3d-3f) with Gaussian peak fitting for indicating the most common pore diameter. Freudenberg I6 and Toray TGP-H-060 substrates show unimodal distribution with primary pore diameter of $17 \mu \mathrm{m}$ and $41.6 \mu \mathrm{m}$, respectively. The SGL 24BA substrate is found to have a bimodal pore size distribution with primary pore diameter of $64.6 \mu \mathrm{m}$ and secondary pore (within the binder area) diameter of $14.6 \mu \mathrm{m}$, partially resolved by the XTM setup with a voxel length size of $2.75 \mu \mathrm{m}$.
Electrochemical performance.-Without the presence of a MPL, the effects ascribable to the selected GDL substrates are isolated and characterized by polarization curves as shown in Fig. 4a. For current densities between 0 and $0.75 \mathrm{~A} \mathrm{~cm}^{-2}$, the cell with Toray GDL performs the best whereas the cell with Freudenberg GDL performs the worst. For current density beyond $0.75 \mathrm{~A} \mathrm{~cm}^{-2}$, the cell with Freudenberg GDL is able to reach high current condition of $1.57 \mathrm{~A} \mathrm{~cm}^{-2}$, while the cell with Toray GDL quickly yields to maximum current conditions below $1 \mathrm{~A} \mathrm{~cm}^{-2}$. The polarization curve of the cell with SGL GDL is consistently between the curves of the cell with Toray and Freudenberg GDL for all current conditions.

In Fig. 4b, cell voltage, current density and high frequency resistance (HFR) time series data are presented for the current jump (CJ) experiments ( 0 to $0.5 \mathrm{~A} \mathrm{~cm}^{-2}$ ) over the duration of $1 \mathrm{~h}$ for the cell with Toray GDL as an example. Performance loss due to X-ray radiation is insignificant with 60 XTM scans distributed over the duration of the imaging experiments as cell voltages in CJ experiments reproduce similar voltage values observed in radiation free $\mathrm{i}-\mathrm{E}$ curve experiments.

Liquid water distribution.-In order to understand the observed influence of GDL substrates on cell performance, subsecond operando XTM imaging was employed to analyze the liquid water distribution in the cathode GDL. XTM slices of the liquid distributions in the 3 different GDL substrates at selected current densities are presented in Fig. 5. It is observed that the different GDL substrate morphologies result in structure-related water distributions. At $100 \mathrm{mV}$ cell condition, a significant liquid water volume can be found under the channels for the cells with Toray and SGL GDLs, which provides qualitative insights for the observed smaller currents at $100 \mathrm{mV}$ conditions in Fig. 4a.

The insights of the single location in-plane slices of Fig. 5 are confirmed by the quantitative in-plane (Fig. 6) and through-plane (Fig. 7) distributions of segmented liquid water. With the increasing of current density, water accumulations are first found in the cathode GDL under the center rib, then emerge and expand to the channels in the SGL and Toray substrates. Nearly no water is presented in the Freudenberg material under the channels even at maximum current 


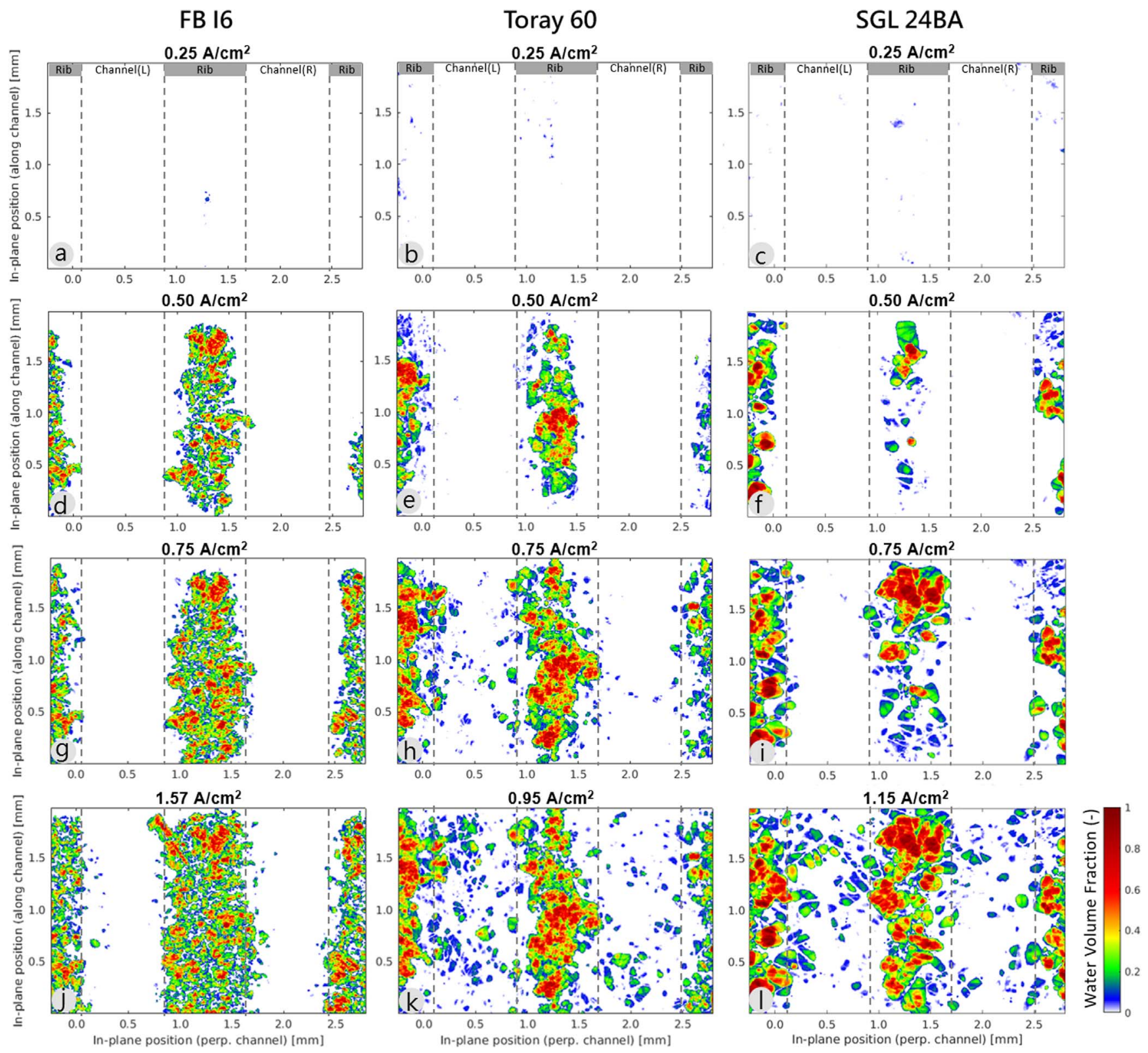

Figure 6. In-plane distribution of water volume fraction of three different GDL substrates at selected current densities $\left(0.25 \mathrm{~A} \mathrm{~cm}^{-2}, 0.5 \mathrm{~A} \mathrm{~cm}{ }^{-2}, 0.75 \mathrm{~A} \mathrm{~cm}{ }^{-2}\right.$, $100 \mathrm{mV}$ ) according to the i-E curves in Fig. 4a.

conditions. These are strong indications of blocked gas delivery due to high saturation near to the catalyst layer in the SGL and Toray GDLs, leading to lower maximum current densities than the Freudenberg GDL. Besides, the water accumulations in the SGL and Toray substrates are more inhomogeneous, compared to the more evenly distributed water in the Freudenberg substrate at various current densities.

The time-resolved XTM data of the current jump experiments illustrates in detail that how individual clusters emerge at different positions and later merge into similar accumulations over time (see in-plane distribution in Fig. 8 and through-plane distribution in Fig. 9). The water accumulates in the same GDL pores regions for all these substrates materials. The water distributions after $15 \mathrm{~min}$ are similar to those during the polarization curve experiments, and remain stable as no significant changes can be observed even after $1 \mathrm{~h}$ holding at $0.5 \mathrm{~A} \mathrm{~cm}^{-2}$.

Total liquid volumes are shown in Figs. 10a-10c for increasing current densities. The SGL substrate shows a slower water volume growth rate at low current densities than the other two GDL materials, probably due to higher vapor phase transport capabilities of its highly porous GDL structure. This can be observed also in Fig. 11c: the SGL substrate reaches a total water volume of only $5 \mathrm{~nL}\left(3.5 \mathrm{nl} \mathrm{mm}^{-2}\right)$ at $0.5 \mathrm{~A} \mathrm{~cm}^{-2}$ compared to $30 \mathrm{~nL}\left(21.1 \mathrm{nl} \mathrm{mm}^{-2}\right)$ for the Freudenberg substrate at the same current condition. It is worth to point out that total liquid volumes under the center rib (CR) for all substrates reach a very similar value of around $45 \mathrm{~nL}\left(31.7 \mathrm{nl} \mathrm{mm}^{-2}\right)$ at the final maximum current conditions (see Figs. 10a-10c). Porosity profiles for dry GDLs under the rib and channels area (see Figs. 10g $-10 \mathrm{i}$ ) suggest that the average porosity of GDLs under the rib is slightly lower than that under the channels, due to the GDL compression effect of the rib at the compression level of around $16 \%$ for all substrates.

In order to characterize operando saturation properties, liquid water saturation profiles are calculated across the GDL thickness and plotted in Figs. 10d-10f for polarization curves. At a relatively low current density of $0.5 \mathrm{~A} \mathrm{~cm}^{-2}$, SGL material shows the lowest saturation value of 0.15 near the catalyst layer compared to that of Freudenberg and Toray materials. Liquid water saturation profiles 
FB I6

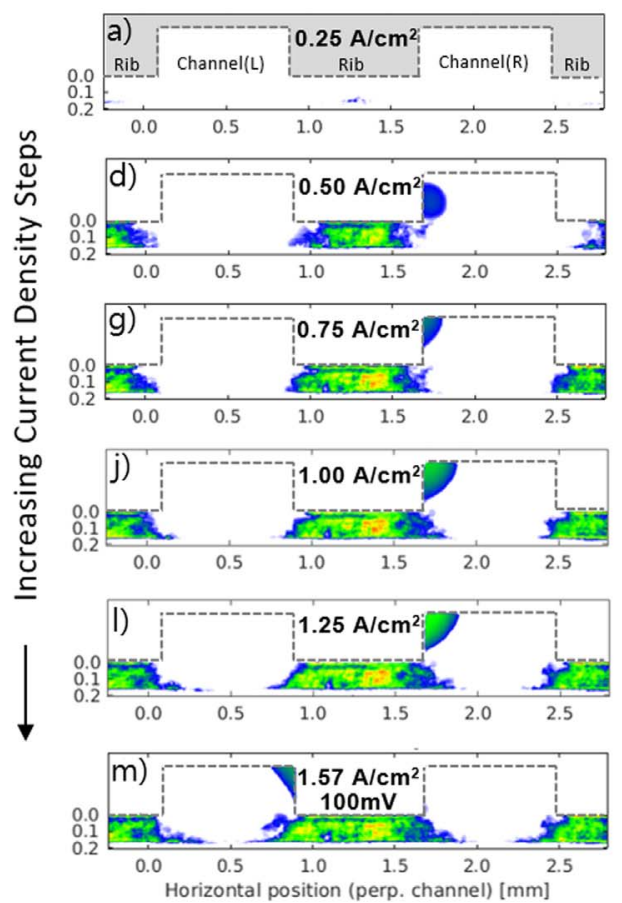

Toray 60
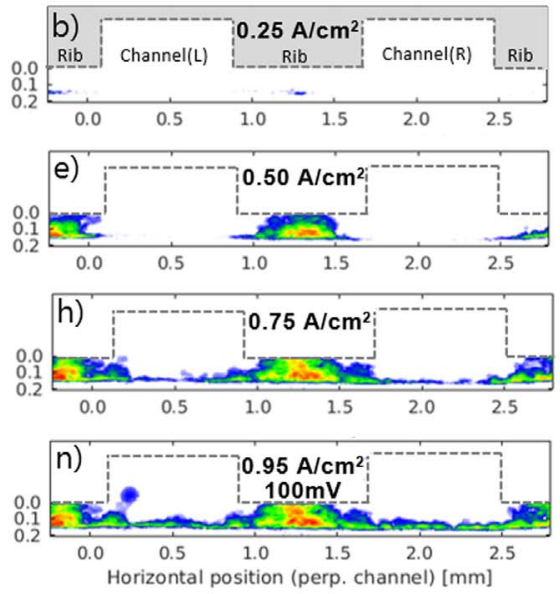

Horizontal position (perp. channel) [mm]
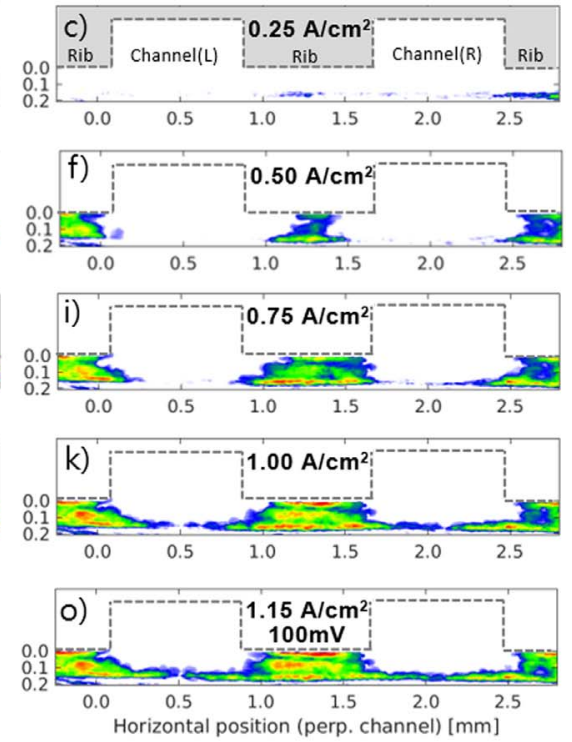

Water Volume Fraction (-)

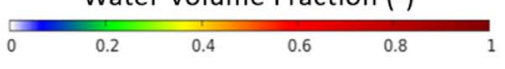

Figure 7. Through-plane distribution of water volume fraction of three different GDL substrates at all current densities according to the i-E curves in Fig. 4a.

stagnate gradually for both the Freudenberg and Toray materials at the current of $0.75 \mathrm{~A} \mathrm{~cm}^{-2}$, while it is not the case for SGL materials. High saturation values of 0.62 (CR GDL) and 0.35 (LC + $\mathrm{RC}$ GDL) are found near the catalyst layer for the Toray material at the highest current density of $0.95 \mathrm{~A} \mathrm{~cm}^{-2}$. This contributes to the worst performance beyond $0.75 \mathrm{~A} \mathrm{~cm}^{-2}$ among the three materials. For the SGL substrate, saturation values of 0.53 (CR GDL) and 0.25 $(\mathrm{LC}+\mathrm{RC}$ GDL) are identified at the same position, leading to a maximum current of $1.15 \mathrm{~A} \mathrm{~cm}^{-2}$. Smaller saturation values of 0.45 (CR GDL) and 0.05 (LC + RC GDL) of the Freudenberg material are found to coincide with the above water volume fraction analysis. Additionally, the water volume profiles for both, Freudenberg and SGL materials, appear flatter than for the Toray substrate, indicating a more homogenous water distribution in the through-plane direction.

The dynamic water saturation profiles of the current jump experiments are presented in Figs. 11d-11f. When observing the entire time period from 0 to $1 \mathrm{~h}$, it is clear that the liquid water volume stagnates after $900 \mathrm{~s}$ for all substrates. Almost the entire water volume is found under the rib area. The SGL GDL shows the lowest saturation over all time steps for the three materials at a current density of $0.5 \mathrm{~A} \mathrm{~cm}^{-2}$. The Freudenberg substrate regulates the water towards the flow field starting from the very first $60 \mathrm{~s}$, while the Toray substrate fails to regulate the water to reach the flow field before $300 \mathrm{~s}$. These findings outline that the lower saturation near the catalyst layer and the flat saturation profile of Freudenberg is a result of the facilitated the water transport through the GDL to the channels and gas transport to catalyst layer remains less obstructed, providing the overall best cell performance beyond $0.75 \mathrm{~A} \mathrm{~cm}^{-2}$ among the three substrates.

Water cluster distributions.-To investigate the distribution of water clusters, water cluster volume vs normalized cumulative cluster volume and normalized cumulative cluster numbers are plotted for the GDL domains under the center rib in Fig. 12 with a logarithmic scale. For the i-E curve conditions the majority $(>90 \%)$ of all water clusters are smaller than $1 \mathrm{~nL}$, while the clusters larger than $1 \mathrm{~nL}$ contain more than $80 \%-90 \%$ water volume (see Figs. 12a, 12d and 12g). The water distributions are highly connected, as for current densities greater or equal $0.5 \mathrm{~A} \mathrm{~cm}^{-2}$ the largest water clusters contain at least $40 \%$ of the total water volume (SGL) or up to $80 \%$ for Toray or some current densities of Freudenberg GDL. The maximum volumes of a single cluster are identified as $38.9 \mathrm{~nL}, 38.7 \mathrm{~nL}$ and $19.1 \mathrm{~nL}$ for Freudenberg, Toray and SGL substrate, respectively. Similar cluster size distributions were also observed by Eller et al. ${ }^{3}$ for Toray type GDL, though the smaller active area in this study restricted the maximal cluster volume.

The time series data of the current jump experiments provides insights into the temporal development of the water distributions and to follow the cluster growth. The cumulative cluster number distribution (Figs. 12b, 12e and 12f) remain rather similar in shape after $30 \mathrm{~s}$ to $60 \mathrm{~s}$, whereas the growth of the larger clusters can be easily followed in the cumulative cluster volume representation (Figs. 12c, 12f and 12i). For the Freudenberg GDL, 6 to 8 clusters are growing ahead of most other clusters from $30 \mathrm{~s}$ to $120 \mathrm{~s}$. The largest cluster tends to grow slightly faster. After $150 \mathrm{~s}$ it covers almost $50 \%$ and after 5 min already more than $80 \%$. Later on, there seem to be some instabilities of the largest cluster, though the total water volume remained rather stable. For the Toray GDL three similar sized clusters are found at $30 \mathrm{~s}$, while later on 3 to 6 clusters account for most of the water volume growth. After $15 \mathrm{~min}$ the largest cluster has reached a share about $80 \%$ of the total water volume. Due to the low saturation in the SGL GDL at $0.5 \mathrm{~A} \mathrm{~cm}^{-2}$, all time steps are dominated by a single water cluster (see Fig. 8). The largest water clusters in the current jump condition reach similar volumes for all GDL types as observed in the i-E curve conditions at the same current density.

Relative diffusivity.-Comprehensive efforts have been made so far through quantitative XTM analysis to understand the electrochemical performance (see Fig. 4a) for the three substrates beyond $0.75 \mathrm{~A} \mathrm{~cm}^{-2}$. The observed discrepancies in cell performances (see Fig. 4a) below $0.75 \mathrm{~A} \mathrm{~cm}^{-2}$ with total saturation below 0.3 remain unclear, which demands gas phase simulation to probe the invisible factors. Considering the XTM-unresolved secondary pore structures 
FB I6
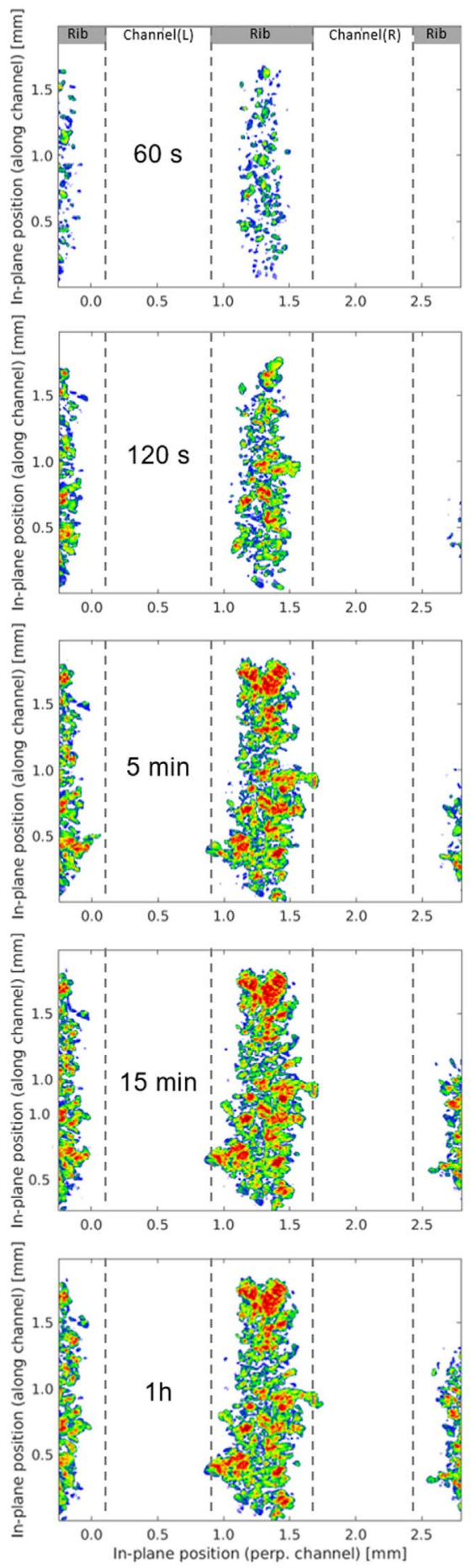

Toray 60
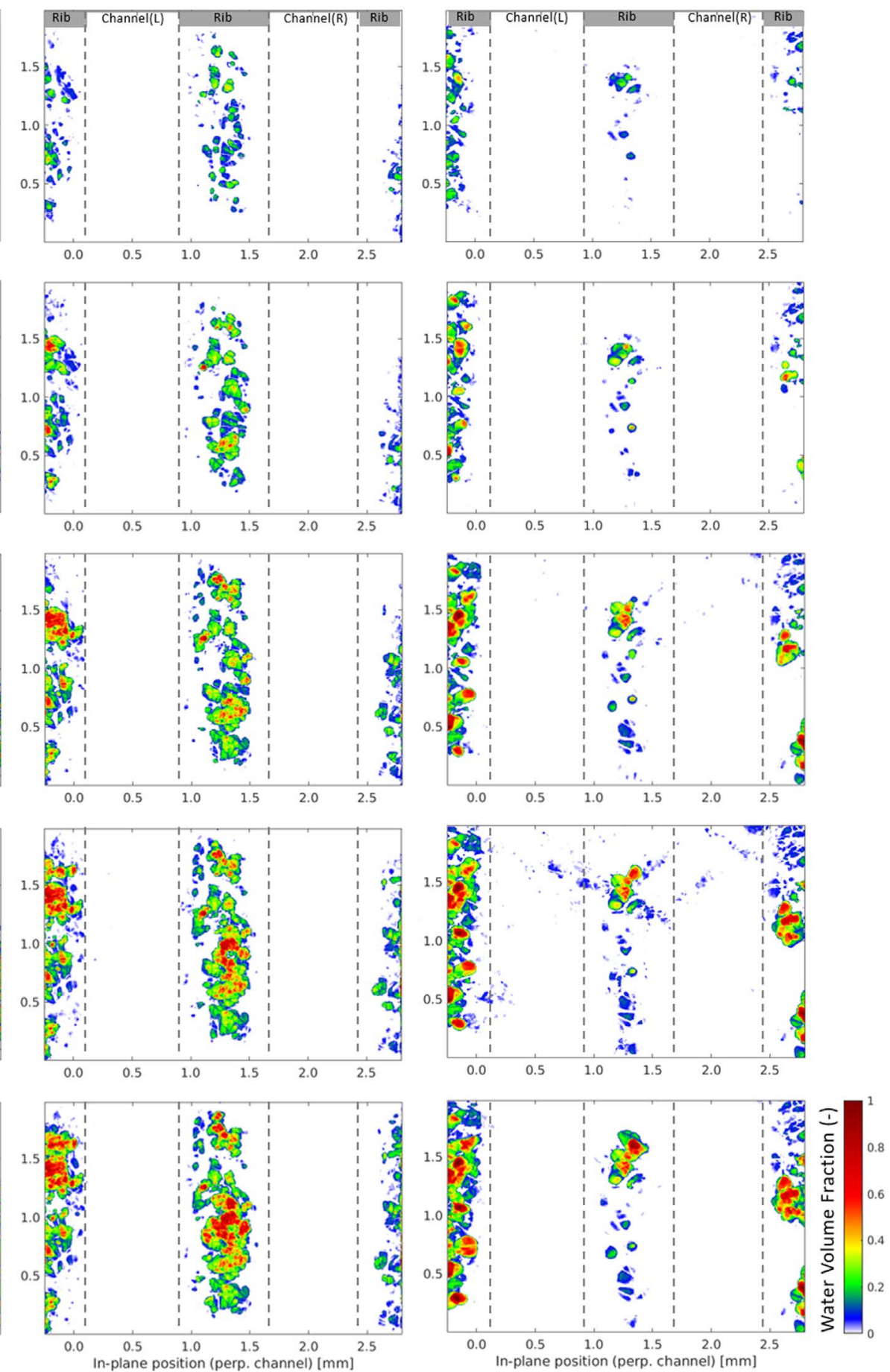

Figure 8. In-plane distribution of time resolved water volume fraction of three different GDL substrates after the current jump from 0 to $0.5 \mathrm{~A} \mathrm{~cm}^{-2}$ at the selected time steps $(60 \mathrm{~s}, 120 \mathrm{~s}, 5 \mathrm{~min}, 15 \mathrm{~min}, 1 \mathrm{~h})$.

of the binder in the SGL substrate, the segmented fiber and pore structure fail to represent the reality precisely when using it as the input for diffusivity simulation and calculation. The SGL substrate was therefore excluded from the following evaluations. Relative diffusivity is calculated and plotted vs current densities of i-E curves and experimental time since current jump from 0 to $0.5 \mathrm{~A} \mathrm{~cm}^{-2}$. Under the ribs, generally decreasing trends of relative diffusivity with increasing current densities are clearly present for both the in-plane (see Fig. 13a) and through-plane (see Fig. 13b) diffusion direction, with a stagnation plateau observed beyond the current density of $0.75 \mathrm{~A} \mathrm{~cm}^{-2}$. It is interesting to point out that the dry Freudenberg substrate has a lower in-plane diffusivity but a higher through-plane diffusivity value than the dry Toray substrate, which is due to the fact that the relative diffusivity of the Freudenberg is rather isotropic, while the Toray GDL shows a clear anisotropy with higher in-plane than through-plane relative diffusivity. As expected, the diffusivities for the compressed GDL area under the center rib show lower values than the less compressed GDL area under the channels. In Figs. 13c-13d, similar in-plane/through-plane diffusivity trends can be found with very similar relative diffusivity values reached at 
FB I6
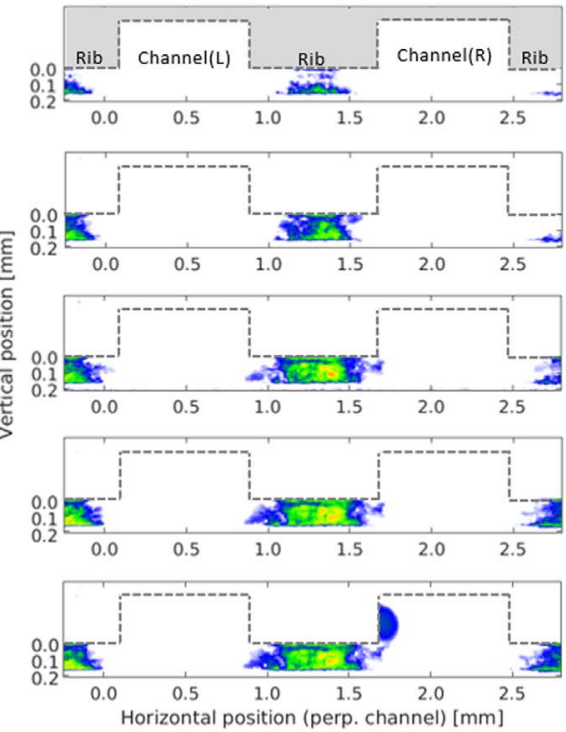

Toray 60
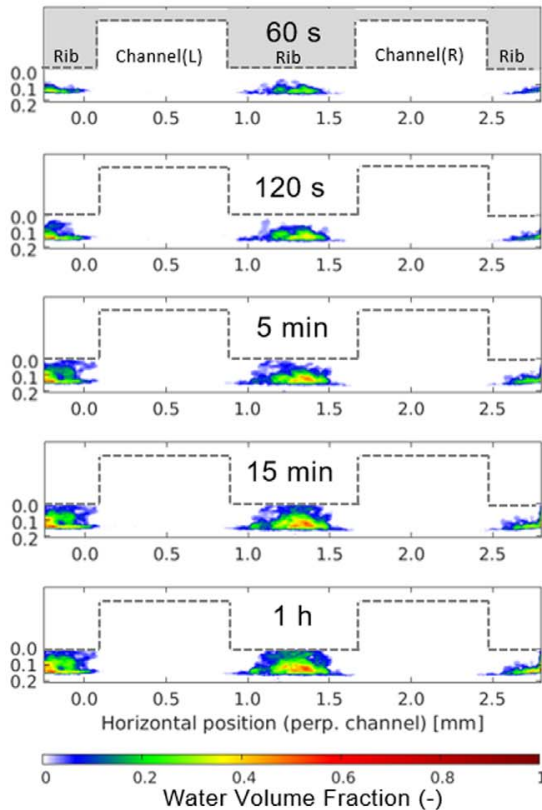

SGL 24BA
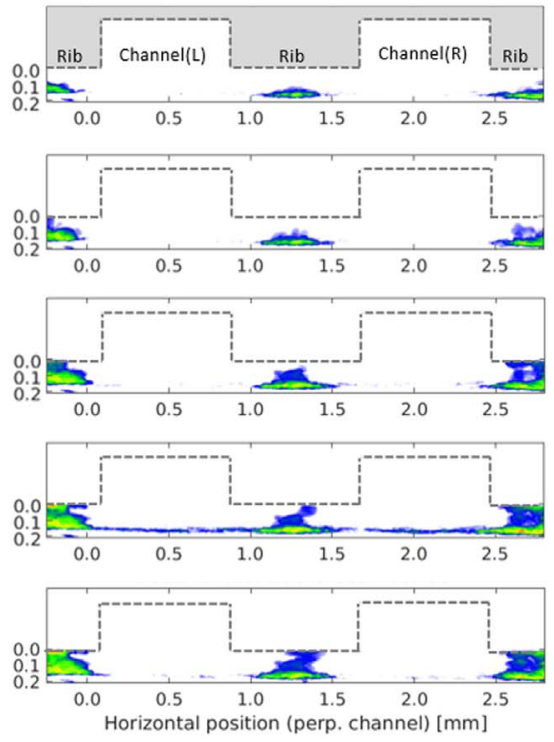

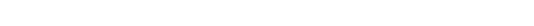

Figure 9. Through-plane distribution of time resolved water volume fraction of the three different GDL substrates after the current jump from 0 to $0.5 \mathrm{~A} \mathrm{~cm}^{-2}$ at the selected time steps $(60 \mathrm{~s}, 120 \mathrm{~s}, 5 \mathrm{~min}, 15 \mathrm{~min}, 1 \mathrm{~h})$.

FB 16
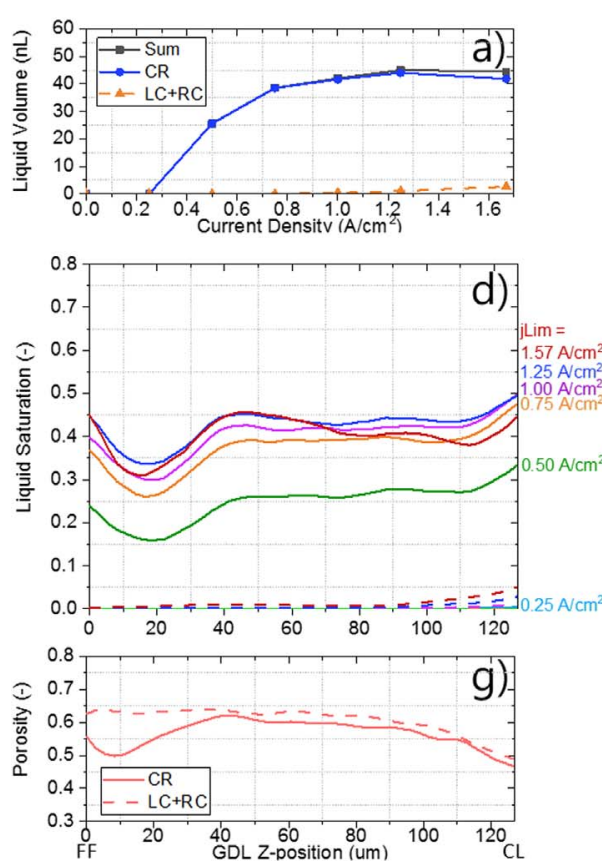

Toray 60
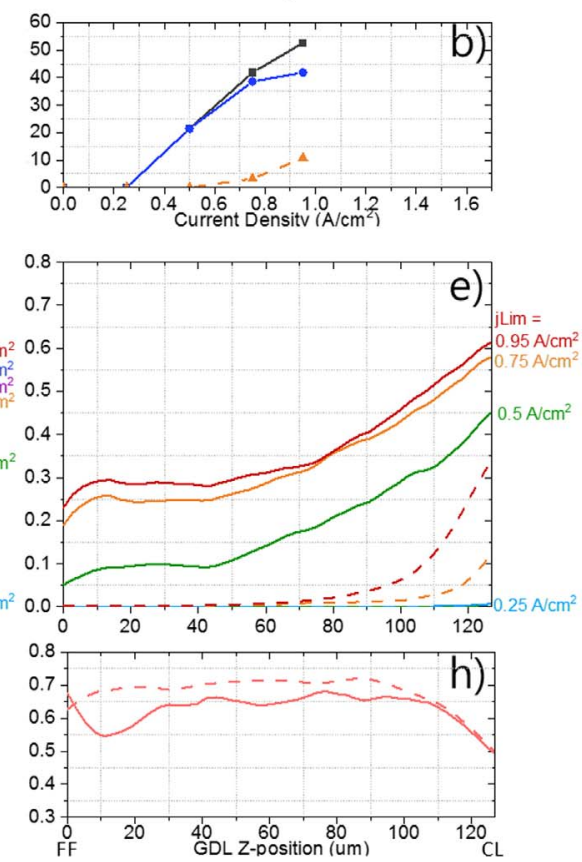

SGL 24BA
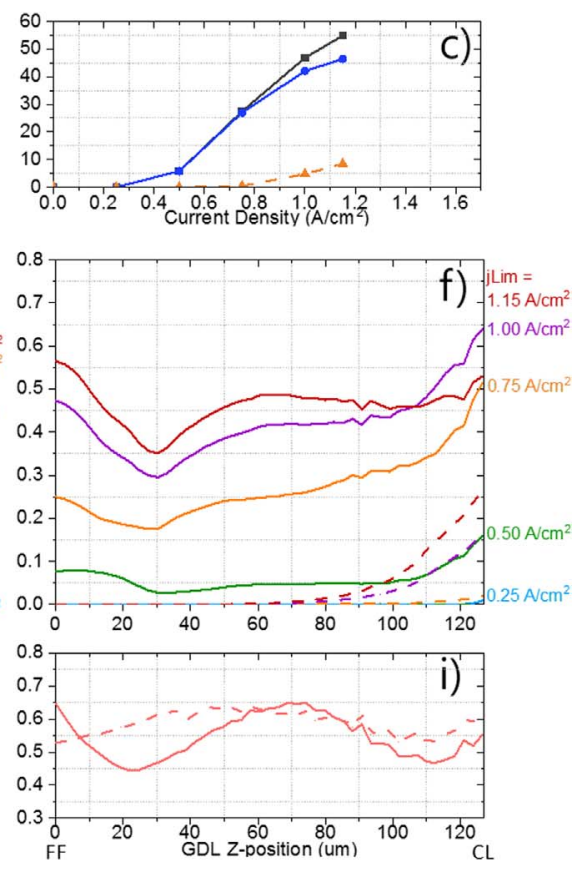

Figure 10. Liquid volume evolution (a)-(c), water saturation profile (d)-(f) of three different GDL substrates at all current densities according to the polarization curve in Fig. 4, and their corresponding porosity profiles (g)-(i). Solid lines represent the analyzed domain under the center rib (CR) and dashed lines the analyzed domain under the channels $(\mathrm{LC}+\mathrm{RC})$.

$0.5 \mathrm{~A} \mathrm{~cm}^{-2}$ in i-E curves and $900 \mathrm{~s}$ in current jump experiments. Stagnated relative diffusivity values were identified after 300-500 s for the domains under the center rib.

To further evaluate the relation between relative diffusivities and saturation values for different substrates and experiments showed in Figs. 14a-14b, the normalized relative diffusivity is introduced with reference to the diffusivity value of the GDL in dry state. In Figs. 14c-14d, the normalized relative diffusivities show an exponential relation versus the term $(1-S)$, the complement of saturation values. This relation can be expressed as:

$$
D_{\text {norm }}^{\text {rel. }}=(1-S)^{\lambda}
$$

where an exponent value $\lambda$ of 2.1 and 1.8 can be identified with exponential fitting for the case of in-plane (IP) diffusion for the Toray and Freudenberg substrates, respectively. In the case of 
FB I6
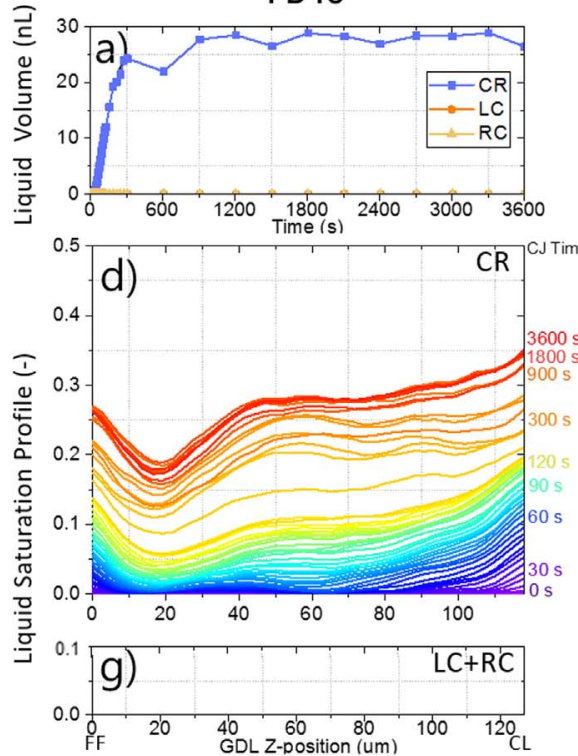

Toray 60

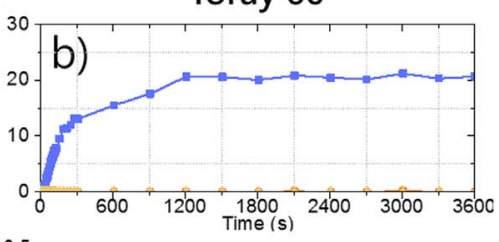

e)

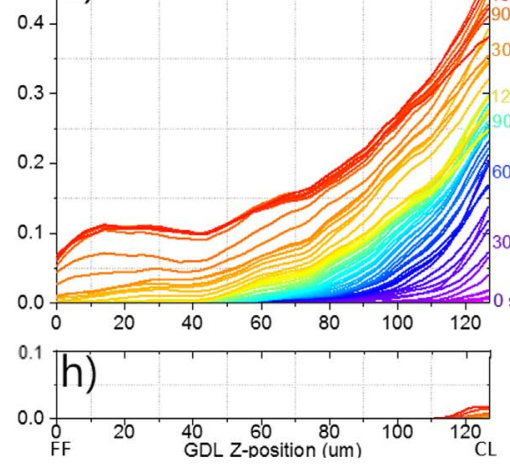

SGL 24BA
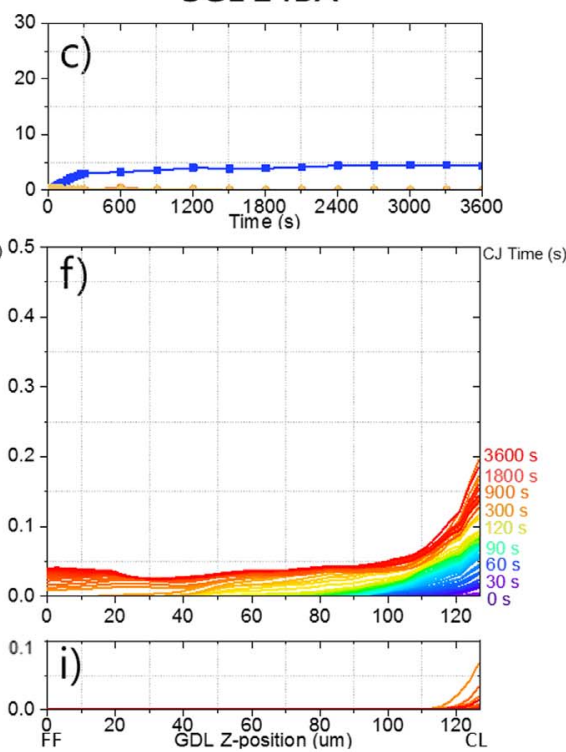

Figure 11. Liquid water volume evolution of the three different GDL substrates from the dry state until $1 \mathrm{~h}$ for the current jump from 0 to $0.5 \mathrm{~A} \mathrm{~cm}^{-2}$ (a)-(c); and their corresponding liquid saturation profile time series for the analyzed domain under the center rib (CR, (d) $-(\mathrm{f}))$ and the left and right channels (LC $+\mathrm{RC}$, (g)-(i)).

\section{i-E Curve}
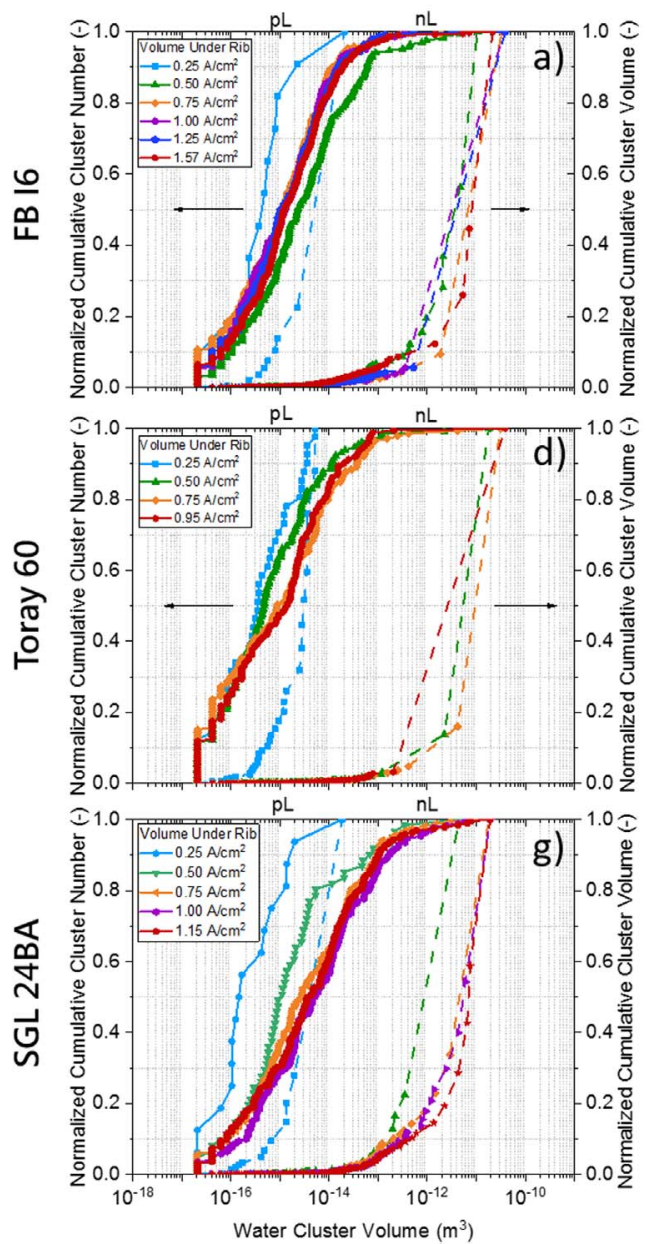

\section{Current Jump}
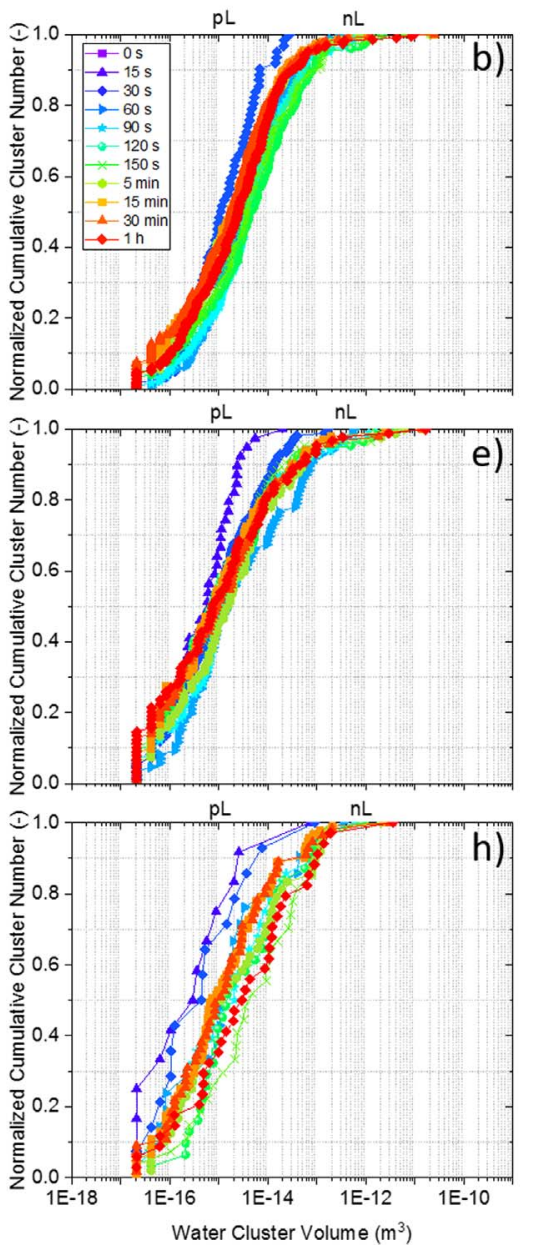
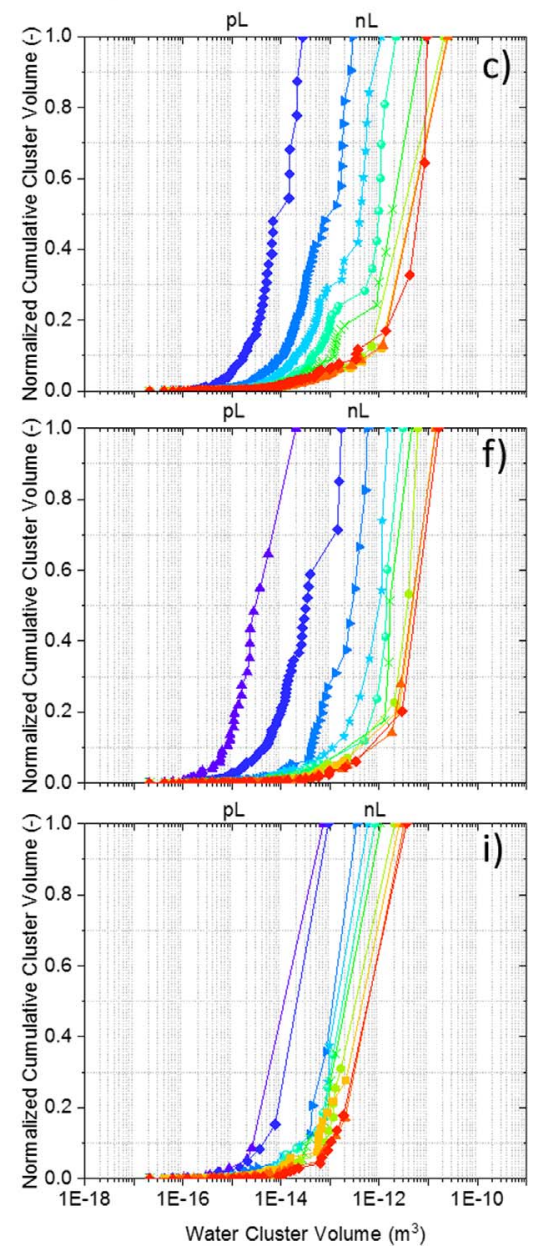

Figure 12. Normalized water cumulative volume and normalized water cumulative cluster number plot for i-E curves (a), (d), (g) and current jump experiments (b), (c); (e), (f); (h), (i). The analyzed domains are located under the center rib (CR) for all three substrates. 

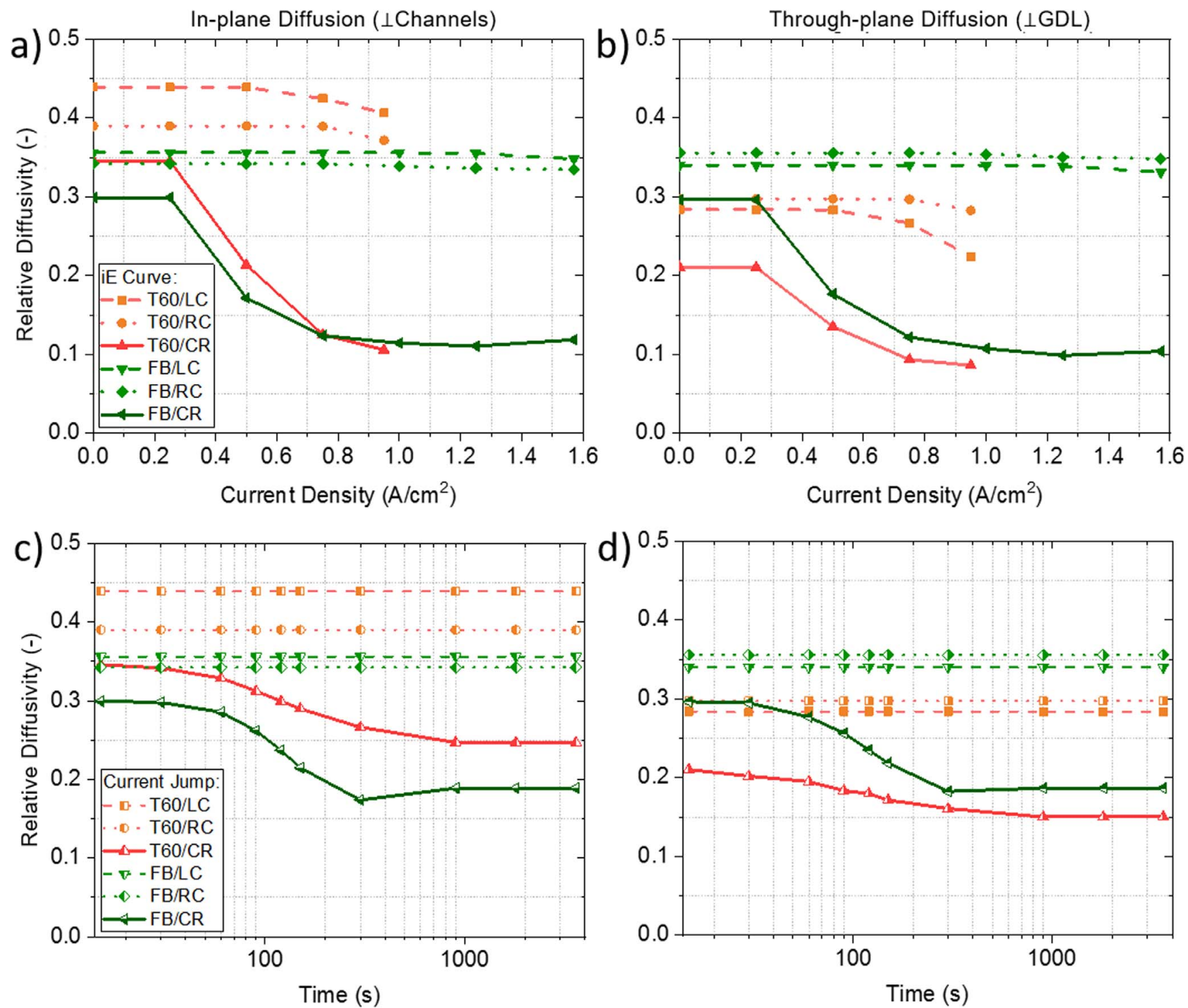

Figure 13. In-plane and through-plane relative diffusivities of Toray TGP-H-060 and Freudenberg I6 substrates vs current densities of i-E curves (a)-(b) and experimental time since current jump from 0 to $0.5 \mathrm{~A} \mathrm{~cm}^{-2}$ (c)-(d). The analyzed domain are classified as center rib (CR), left channel (LC) and right channel (RC).

through-plane (TP) diffusion, the exponent value $\lambda$ is derived as 2.0 and 1.8 for the Toray and Freudenberg substrates respectively, including all data points. If only i-E curve information is considered, then $\lambda$ would be would be very similar for Toray and Freudenberg in the TP-direction with a value of about 2.0.

\section{Discussion}

The observed differences in saturation and electrochemical performance with different GDL substrate types demand the challenging investigation of possible determining factors at different current densities. Since no MPL is applied to isolate the GDL substrate effects, the material properties are intrinsically different in terms of fiber structures, average pore sizes and pore morphologies (Fig. 3), resulting in different liquid saturation and gas diffusion dynamics during cell operation. The collective effects governed by both intrinsic and dynamic factors define the cell performances at different operation conditions.

At the low current density conditions of $0.25 \mathrm{~A} \mathrm{~cm}^{-2}$ the water removal in the gas phase is sufficient to keep the dew point below the local temperature in the GDL and to avoid more or less completely condensing conditions in all three GDL substrates. Already at $0.5 \mathrm{~A} \mathrm{~cm}^{-2}$ first liquid water accumulations were found under the ribs - both for iE-curve and current jump conditions. For the present cell geometry the diffusive path through the GDL is about three times longer from the center of the rib to the flow field channel than through-plane from the catalyst-GDL interface to the GDL-channel interface thus condensing conditions and liquid water accumulations are established first under the ribs. Rashapov and Gostick $^{49}$ reported an in-plane relative diffusivity of 0.6 present in the channel area for SGL 24BA at a compression level of $19 \%$, which is much higher than 0.3 and 0.34 for Freudenberg I6 and Toray TGP-H-060 GDL at $17 \%$ and $16 \%$ compression, respectively. The higher relative diffusivity of SGL 24BA promotes the diffusive gas phase water transport in SGL 24BA GDL and is likely to explain the lower saturation level at $0.5 \mathrm{~A} \mathrm{~cm}^{-2}$ compared to the Freudenberg and Toray cell.

The difference in GDL saturation at current densities of about $1 \mathrm{~A} \mathrm{~cm}^{-2}$ and higher remains difficult to explain by pore morphology and GDL relative diffusivity. It seems more likely that differences in the GDL thermal conductivity need to be considered, as it has a significant influence on the formation of liquid water and potential 

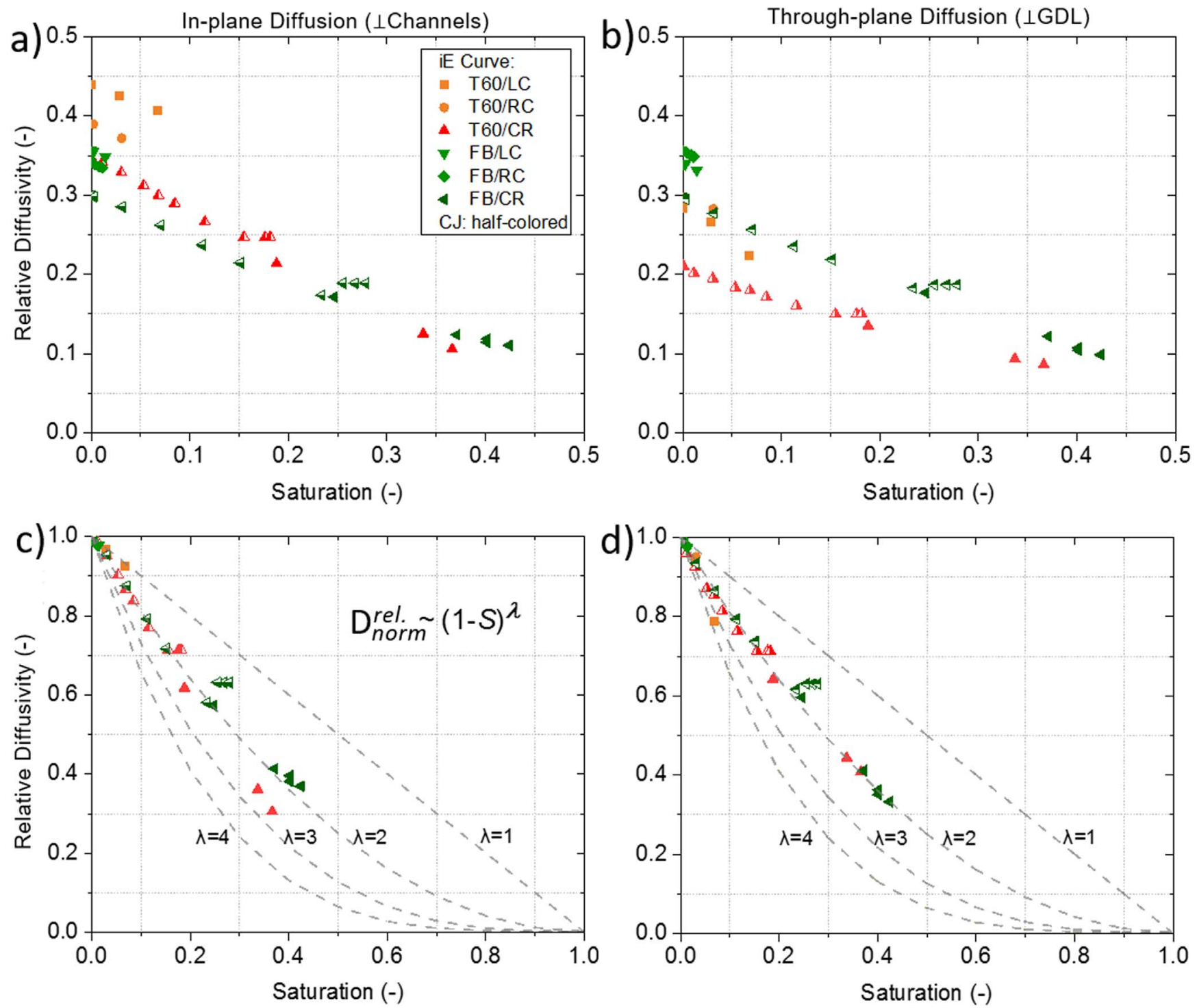

Figure 14. (a)-(b) Through-plane and in-plane relative diffusivities vs saturation values for Toray TGP-H-060 and Freudenberg I6 GDL substrates at all current densities according to the i-E curve and current jump experiments; (c)-(d) normalized relative diffusivities to dry status values vs the corresponding saturation values. The analyzed domain are classified as center rib (CR), left channel (LC) and right channel (RC). The grey dashed lines in figure (c) and (d) represent the relation between the normalized relative diffusivity and saturation given by $D_{\text {norm }}^{\text {rel. }}=(1-S)^{\lambda}$ when $\lambda$ equals to $1,2,3$ and 4 .

heat pipe effects as well. ${ }^{50} \mathrm{~A}$ much lower through-plane thermal conductivity is reported for Freudenberg $\left(0.15 \mathrm{~W} \mathrm{~m}^{-1} \mathrm{~K}^{-1}\right)$ compared to about $0.5 \mathrm{~W} \mathrm{~m}^{-1} \mathrm{~K}^{-1}$ (SGL) and $0.6 \mathrm{~W} \mathrm{~m}^{-1} \mathrm{~K}^{-1}$ (Toray) at the actual compression ratios ${ }^{51,52}$ which would result in a temperature gradient of about $10 \mathrm{~K}$ between the catalyst-GDL and GDL-gas channel interfaces at a heat production rate of about $1 \mathrm{~W} \mathrm{~cm}^{-2}$. The strong temperature gradient that can be expected for Freudenberg GDL seems to prevent condensing conditions in the whole channel GDL at $1 \mathrm{~A} \mathrm{~cm}^{-2}$ and parts of the center channel GDL even at $1.6 \mathrm{~A}$ $\mathrm{cm}^{-2}$ and thereby enable the higher cell voltages at these current densities. The higher thermal conductivities of the SGL and Toray substrates lead to lower temperature gradients in the GDL domain and allow for condensing conditions and water accumulations (see Figs. 10e and 10f) over the whole channel width at the catalystGDL interface at $>=1 \mathrm{~A} \mathrm{~cm}^{-2}$ even at the present dry inlet gas conditions. The strong in-plane orientation of the carbon fibers in the Toray GDL will further decrease channel-rib temperature gradients and may explain the water film formation at the catalyst-GDL interface under the channel already at $0.75 \mathrm{~A} \mathrm{~cm}^{-2}$ and the steep decay in cell voltage soon afterwards.

Correlations between saturation values and normalized relative diffusivities are often expressed by the exponent $\lambda$, the power law formulation, representing the diffusivity reduction due to the presence of water in the GDL substrate. A large value of $\lambda$ means that the diffusivity is reduced more significantly due to the liquid saturation. The value of $\lambda=2.1$ for in-plane diffusion of Toray TGP-H-060 (10 \% PTFE) concurs well with previous findings $(\lambda=2.0)$ for a Toray TGP-H-060 substrate (20\% PTFE) reported by Rosen et al. ${ }^{53}$ The $\lambda$ value of 2.0 for through-plane diffusivity, suggests that there is no significant difference between normalized in-plane and through-plane diffusivities with same water saturation. Our study also provides $\lambda$ values for Freudenberg I6 GDL with waterjet entangled fibers oriented both in-plane and throughplane direction. Similar $\lambda$ values of 1.8 and 1.8 were found for the inplane and through-plane diffusion case, indicating that there is also no significant difference of the through-plane and in-plane diffusivity with the presence of liquid water in the Freudenberg substrate. 


\section{Conclusions}

The underlying critical structure factors of three representative commercial GDL substrates all without MPL (Freudenberg H2315 I6, Toray TGP-H-060 and SGL 24BA) on PEFC performance at the typical start-up temperature of $25{ }^{\circ} \mathrm{C}$ are investigated through the analysis of the liquid water accumulating in the GDL pore space. The cells were operated at differential cell conditions to mimic cell inlet conditions with dry cathode feed gas, as it is the case if no humidifier is implemented in the PEFC peripherals, and wet anode feed gas due to hydrogen recirculation at the anode. Polarization curves and current jumps were analyzed by subsecond operando X-ray tomographic microscopy (XTM) scans with a duration of $0.1 \mathrm{~s}$ to capture both static and dynamic water distributions. Paganin prefiltered projections were used for X-ray tomographic microscopy reconstructions to reduce image noise and to retrieve the liquid water phase from the noisy images with minimized artifacts. The cathode GDL domains were analyzed separately for rib and channel areas of the flow fields.

The Freudenberg I6, Toray TGP-H-060 and SGL 24BA GDL materials have increasing average pore diameters of $17 \mu \mathrm{m}, 42 \mu \mathrm{m}$ and $65 \mu \mathrm{m}$, resulting in fine grained water clusters of the liquid water distributions according to the different GDL pore morphologies. The water accumulations in the GDL were mainly observed under the ribs, while the channels had much lower saturation levels or remained even completely dry at the selected inlet conditions. Under the ribs, first liquid water accumulations were detected at $0.5 \mathrm{~A} \mathrm{~cm}^{-2}$, with average saturation values of $24 \%$ (Freudenberg), $19 \%$ (Toray) and 6\% (SGL). In the dynamic current jump characterizations, the water distributions after $1 \mathrm{~h}$ holding at $0.5 \mathrm{~A} \mathrm{~cm}^{-2}$ were similar to that during the polarization curve experiments, providing evidence of reproducible percolation paths of the liquid distributions. In both static and dynamic characterizations, the SGL material shows a much lower saturation near the catalyst layer at this current density which seems due to the higher relative diffusivity of the dry SGL GDL structure.

The three substrates showed different through-plane water distribution profiles. While the water saturation in the Freudenberg GDL was found rather homogeneous over the whole GDL thickness soon after cell operation and also at higher current densities, the saturation in the Toray GDL showed a distinct increase towards the catalyst layer with saturation values of up to $62 \%$ at the GDLcatalyst layer interface. SGL showed a plateau like distribution for low current density $\left(0.5 \mathrm{~A} \mathrm{~cm}^{-2}\right)$, but more valley like profiles at higher current densities $\left(>0.75 \mathrm{~A} \mathrm{~cm}^{-2}\right)$.

The current densities that were achieved at $100 \mathrm{mV}$ for Freudenberg $\left(1.6 \mathrm{~A} \mathrm{~cm}^{-2}\right)$, Toray $\left(1.0 \mathrm{~A} \mathrm{~cm}^{-2}\right)$ and SGL (1.2 A $\mathrm{cm}^{-2}$ ) don't seem to correlate with the detected water saturation levels of $40 \%, 36 \%$ and $46 \%$ under the ribs, but with channel GDL saturation. There, the saturation is lowest $(2 \%)$ for Freudenberg, which reaches the highest current density, highest for Toray $(8 \%$ saturation) with the lowest current density and intermediate saturation $(4 \%)$ and current density for SGL. In particular, also the saturation at the GDL-catalyst layer interface follows the same trend, even more pronounced with $4 \%$ for Freudenberg, $33 \%$ for Toray and $25 \%$ for SGL.

The reason for the low channel GDL saturation at the highest current density of the Freudenberg GDL remains difficult to explain by the differences in pore morphology and related relative diffusivity values. Presumably, the low thermal conductivity of the Freudenberg GDL results in significant temperature gradients between channel and rib domain, but also between catalyst layer and flow field channels, which seems to promote water removal in vapor phase and enable high current densities. ${ }^{54}$

The relative diffusivity as function of saturation was determined using direct numerical simulations on the voxel data for the Freudenberg and Toray GDLs. For both GDL types a power law exponent of about two was found both for in-plane and throughplane direction.
Thanks to the systematic comparison of three different GDL materials, this work provides fundamental insights into the structureproperty relationship linking microstructural GDL properties and PEFC performance that is necessary to guide GDL development and additionally supports the modelling community with a solid base of experimental validation data. To further understand the dominating factors essentially for PEFC performance, experiments at different operating temperatures, and particularly with MPL layer applied to the three GDL substrates will need to be undertaken in the future.

\section{Acknowledgments}

Financial support from the Swiss National Science Foundation (SNF) under grant No. 200021 166064, software and electronic support by $\mathrm{T}$. Gloor, and support during measuring campaigns at the TOMCAT beamline by G. Mikuljan, A. Mularczyk, M. Striednig, C. Csoklich, T. Schuler and J. Halter are gratefully acknowledged. We acknowledge the Paul Scherrer Institut, Villigen, Switzerland for provision of synchrotron radiation beamtime at the TOMCAT beamline of the Swiss Light Source.

\section{ORCID}

Hong Xu (iD https://orcid.org/0000-0001-7039-1797

Felix N. Büchi (iD https://orcid.org/0000-0002-3541-4591

Jens Eller (iD https://orcid.org/0000-0002-9348-984X

\section{References}

1. M. F. Mathias, J. Roth, J. Fleming, and W. Lehnert, "Diffusion media materials and characterisation." Handbook of Fuel Cells (Wiley, New Jersey, NJ) (2010).

2. L. Cindrella, A. M. Kannan, J. F. Lin, K. Saminathan, Y. Ho, C. W. Lin, and J. Wertz, "Gas diffusion layer for proton exchange membrane fuel cells-a review." J. Power Sources, 194, 146 (2009).

3. J. Eller, J. Roth, F. Marone, M. Stampanoni, and F. N. Büchi, "Operando properties of gas diffusion layers: saturation and liquid permeability." J. Electrochem. Soc., 164, F115 (2016)

4. Y. Nagai, J. Eller, T. Hatanaka, S. Yamaguchi, S. Kato, A. Kato, F. Marone, H. Xu and F. N. Büchi, "Improving water management in fuel cells through microporous layer modifications: fast operando tomographic imaging of liquid water." J. Power Sources, 435, 226809 (2019).

5. J. Park, H. Oh, Y. I. Lee, K. Min, E. Lee, and J.-Y. Jyoung, "Effect of the pore size variation in the substrate of the gas diffusion layer on water management and fuel cell performance." Appl. Energy, 171, 200 (2016).

6. J. Hinebaugh, Z. Fishman, and A. Bazylak, "Unstructured pore network modeling with heterogeneous PEMFC GDL porosity distributions." J. Electrochem. Soc., 157, B1651 (2010)

7. J. T. Gostick, M. A. Ioannidis, M. W. Fowler, and M. D. Pritzker, "Pore network modeling of fibrous gas diffusion layers for polymer electrolyte membrane fue cells." J. Power Sources, 173, 277 (2007).

8. T. Arlt, M. Klages, M. Messerschmidt, J. Scholta, and I. Manke, "Influence of artificially aged gas diffusion layers on the water management of polymer electrolyte membrane fuel cells analyzed with in-operando synchrotron imaging." Energy, 118, 502 (2017)

9. E. E. Kimball, J. B. Benziger, and Y. G. Kevrekidis, "Effects of GDL structure with an efficient approach to the management of liquid water in PEM fuel cells." Fuel Cells, 10, 530 (2010)

10. P. K. Sinha, P. P. Mukherjee, and C.-Y. Wang, "Impact of GDL structure and wettability on water management in polymer electrolyte fuel cells." J. Mater. Chem., 17, 3089 (2007)

11. J. Yablecki, J. Hinebaugh, and A. Bazylak, "Effect of liquid water presence on PEMFC GDL effective thermal conductivity." J. Electrochem. Soc., 159, F805 (2012).

12. I. V. Zenyuk and A. Z. Weber, "Understanding liquid-water management in PEFCs using X-ray computed tomography and modeling." ECS Trans., 69, 1253 (2015).

13. P. Deevanhxay, T. Sasabe, S. Tsushima, and S. Hirai, "Effect of liquid wate distribution in gas diffusion media with and without microporous layer on PEM fuel cell performance." Electrochem. Commun., 34, 239 (2013).

14. J. Zhou, S. Shukla, A. Putz, and M. Secanell, "Analysis of the role of the microporous layer in improving polymer electrolyte fuel cell performance." Electrochim. Acta, 268, 366 (2018).

15. F. S. Nanadegani, E. N. Lay, and B. Sunden, "Effects of an MPL on water and thermal management in a PEMFC." Int. J. Energy Res., 43, 274 (2019).

16. I. V. Zenyuk, D. Y. Parkinson, L. G. Connolly, and A. Z. Weber, "Gas-diffusionlayer structural properties under compression via X-ray tomography." J. Power Sources, 328, 364 (2016).

17. Z. Fishman, J. Hinebaugh, and A. Bazylak, "Microscale tomography investigations of heterogeneous porosity distributions of PEMFC GDLs." J. Electrochem. Soc., 157, B1643 (2010). 
18. R. Banerjee, J. Hinebaugh, H. Liu, R. Yip, N. Ge, and A. Bazylak, "Heterogeneous porosity distributions of polymer electrolyte membrane fuel cell gas diffusion layer materials with rib-channel compression." Int. J. Hydrogen Energy, 41, 14885 (2016).

19. S.-G. Kim and S.-J. Lee, "Tomographic analysis of porosity variation in gas diffusion layer under freeze-thaw cycles." Int. J. Hydrogen Energy, 37, 566 (2012)

20. N. Khajeh-Hosseini-Dalasm, T. Sasabe, T. Tokumasu, and U. Pasaogullari, "Effects of polytetrafluoroethylene treatment and compression on gas diffusion layer microstructure using high-resolution X-ray computed tomography." J. Power Sources, 266, 213 (2014)

21. S. Chevalier, J. Lee, N. Ge, R. Yip, P. Antonacci, Y. Tabuchi, T. Kotaka, and A. Bazylak, "In operando measurements of liquid water saturation distributions and effective diffusivities of polymer electrolyte membrane fuel cell gas diffusion layers." Electrochim. Acta, 210, 792 (2016).

22. C. Tötzke et al., "Three-dimensional study of compressed gas diffusion layers using synchrotron X-ray imaging." J. Power Sources, 253, 123 (2014).

23. H. Ostadi, P. Rama, Y. Liu, R. Chen, X. Zhang, and K. Jiang, "Nanotomography based study of gas diffusion layers." Microelectron. Eng., 87, 1640 (2010).

24. P. Rama, Y. Liu, R. Chen, H. Ostadi, K. Jiang, X. Zhang, Y. Gao, P. Grassini, and D. Brivio, "Determination of the anisotropic permeability of a carbon cloth gas diffusion layer through X-ray computer micro-tomography and single-phase lattice Boltzmann simulation.” Int. J. Numer. Methods Fluids, 67, 518 (2011)

25. I. V. Zenyuk, D. Y. Parkinson, G. Hwang, and A. Z. Weber, "Probing water distribution in compressed fuel-cell gas-diffusion layers using $\mathrm{X}$-ray computed tomography." Electrochem. Commun., 53, 24 (2015).

26. A. Lamibrac, J. Roth, M. Toulec, F. Marone, M. Stampanoni, and F. N. Büchi, "Characterization of liquid water saturation in gas diffusion layers by X-ray tomographic microscopy." J. Electrochem. Soc., 163, F202 (2015)

27. J. T. Gostick, H. Gunterman, B. Kienitz, J. Newman, A. MacDowell, and A. Weber, "Tomographic imaging of water injection and withdrawal in PEMFC gas diffusion layers." ECS Trans., 33, 1407 (2019).

28. U. U. Ince et al., "Effects of compression on water distribution in gas diffusion layer materials of PEMFC in a point injection device by means of synchrotron X-ray imaging." Int. J. Hydrogen Energy, 43, 391 (2018).

29. A. Mularczyk, Q. Lin, M. J. Blunt, A. Lamibrac, F. Marone, T. J. Schmidt F. N. Büchi, and J. Eller, "Droplet and percolation network interactions in a fuel cel gas diffusion layer." J. Electrochem. Soc., 167, 084506 (2020).

30. P. Krüger, H. Markötter, J. Haußmann, M. Klages, T. Arlt, J. Banhart, C. Hartnig, I. Manke, and J. Scholta, "Synchrotron X-ray tomography for investigations of water distribution in polymer electrolyte membrane fuel cells." J. Power Sources, 196, 5250 (2011)

31. P. Shrestha, C. H. Lee, K. F. Fahy, M. Balakrishnan, N. Ge, and A. Bazylak, "Formation of Liquid water pathways in PEM fuel cells: a 3-D pore-scale perspective." J. Electrochem. Soc., 167, 054516 (2020).

32. H. Xu, S. Nagashima, H. P. Nguyen, K. Kishita, F. Marone, F. N. Büchi, and J. Eller, "Temperature dependent water transport mechanism in gas diffusion layer revealed by subsecond operando X-ray tomographic microscopy." J. Power Sources, 490, 229492 (2021).

33. S. Park, J.-W. Lee, and B. N. Popov, "A review of gas diffusion layer in PEM fuel cells: Materials and designs." Int. J. Hydrogen Energy, 37, 5850 (2012).

34. T. Kitahara, T. Konomi, M. Murata, N. Berg, and P. Wilde, "Influences of gas diffusion layer design parameters on the performance of polymer electrolyte fuel cells." ECS Trans., 5, 27 (2007)
35. I. Mayrhuber, F. Marone, M. Stampanoni, T. J. Schmidt, and F. N. Büchi, "Fast X ray tomographic microscopy: investigating mechanisms of performance drop during freeze starts of polymer electrolyte fuel cells." ChemElectroChem, 2, 1551 (2015).

36. M. Stampanoni et al., "Trends in synchrotron-based tomographic imaging: the SLS experience." Proc. SPIE (2006).

37. M. Bührer, M. Stampanoni, X. Rochet, F. Büchi, J. Eller, and F. Marone, "Highnumerical-aperture macroscope optics for time-resolved experiments." J. Synchrotron Radiat., 26, 1161 (2019).

38. R. Mokso et al., "GigaFRoST: the gigabit fast readout system for tomography." J. Synchrotron Radiat., 24, 1250 (2017).

39. D. Paganin, S. C. Mayo, T. E. Gureyev, P. R. Miller, and S. W. Wilkins, "Simultaneous phase and amplitude extraction from a single defocused image of a homogeneous object." J. Microsc., 206, 33 (2002).

40. F. Marone and M. Stampanoni, "Regridding reconstruction algorithm for real-time tomographic imaging." J. Synchrotron Radiat., 19, 1029 (2012).

41. P. Perona and J. Malik, "Scale-space and edge detection using anisotropic diffusion." IEEE Transactions on pattern analysis machine intelligence, 12, 629 (1990)

42. A. Kaestner, E. Lehmann, and M. Stampanoni, "Imaging and image processing in porous media research." Adv. Water Res., 31, 1174 (2008).

43. C. Carminati, M. Strobl, and A. Kaestner, "KipTool, a general purpose processing tool for neutron imaging data." SoftwareX, 10, 100279 (2019).

44. B. Münch and L. Holzer, "Contradicting geometrical concepts in pore size analysi attained with electron microscopy and mercury intrusion." J. Am. Ceram. Soc., 91, 4059 (2008).

45. J. Schindelin, I. Arganda-Carreras, E. Frise, V. Kaynig, M. Longair, T. Pietzsch S. Preibisch, C. Rueden, S. Saalfeld, and B. Schmid, "Fiji: an open-source platform for biological-image analysis." Nat. Methods, 9, 676 (2012).

46. S. Van der Walt, J. L. Schönberger, J. Nunez-Iglesias, F. Boulogne, J. D. Warner, N. Yager, E. Gouillart, and T. Yu, "scikit-image: image processing in Python." PeerJ, 2, e453 (2014).

47. V. D. Bruggeman, "Berechnung verschiedener physikalischer Konstanten von heterogenen substanzen. I. Dielektrizitätskonstanten und Leitfähigkeiten der Mischkörper aus isotropen substanzen." J. Annalen der physik, 416, 636 (1935).

48. J. Becker, C. Wieser, S. Fell, and K. Steiner, "A multi-scale approach to materia modeling of fuel cell diffusion media." International Journal of Heat Mass Transfer, 54, 1360 (2011)

49. R. R. Rashapov and J. T. Gostick, "In-plane effective diffusivity in PEMFC gas diffusion layers." Transp. Porous Media, 115, 411 (2016).

50. A. Z. Weber and M. A. Hickner, "Modeling and high-resolution-imaging studies of water-content profiles in a polymer-electrolyte-fuel-cell membrane-electrode assembly." Electrochim. Acta, 53, 7668 (2008).

51. H. Sadeghifar, N. Djilali, and M. Bahrami, "Effect of Polytetrafluoroethylene (PTFE) and micro porous layer (MPL) on thermal conductivity of fuel cell gas diffusion layers: Modeling and experiments." J. Power Sources, 248, 632 (2014).

52. O. S. Burheim, J. G. Pharoah, H. Lampert, P. J. S. Vie, and S. Kjelstrup, "Through plane thermal conductivity of PEMFC porous transport layers." J. Fuel Cell Sci. Technol., 8, 021013 (2010).

53. T. Rosén, J. Eller, J. Kang, N. I. Prasianakis, J. Mantzaras, and F. N. Büchi, "Saturation dependent effective transport properties of PEFC gas diffusion layers." J. Electrochem. Soc., 159 (2012)F536.

54. C. Simon, "Oxygen and water transport in the microporous layer of polymer electrolyte membrane fuel cells." PhD Thesis, Technische Universität München, Munich, Germany (2020). 